\title{
Ginkgolide B-induced AMPK pathway activation protects astrocytes by regulating endoplasmic reticulum stress, oxidative stress and energy metabolism induced by $\mathbf{A} \boldsymbol{\beta}_{1-42}$
}

\author{
JING WANG $^{1-4}$, YAN DING ${ }^{1,2}$, LINWU ZHUANG ${ }^{1,2}$, ZHENZHONG WANG $^{3,4}$, WEI XIAO ${ }^{3,4}$ and JINGBO ZHU ${ }^{1,2}$ \\ ${ }^{1}$ School of Food Science and Technology and ${ }^{2}$ Institute of Chemistry and Applications of Plant Resources, \\ Dalian Polytechnic University, Dalian, Liaoning 116034; ${ }^{3}$ Jiangsu Kanion Pharmaceutical Co. Ltd.; ${ }^{4}$ State Key Laboratory \\ of Pharmaceutical New-tech for Chinese Medicine, Lianyungang, Jiangsu 222000, P.R. China
}

Received July 20, 2020; Accepted January 11, 2021

DOI: $10.3892 / \mathrm{mmr} .2021 .12096$

\begin{abstract}
Ginkgolide B (GB), the diterpenoid lactone compound isolated from the extracts of Ginkgo biloba leaves, significantly improves cognitive impairment, but its potential pharmacological effect on astrocytes induced by $\beta$-amyloid $(\mathrm{A} \beta)_{1-42}$ remains to be elucidated. The present study aimed to investigate the protective effect and mechanism of GB on astrocytes with $\mathrm{A} \beta_{1-42}$-induced apoptosis in Alzheimer's disease (AD). Astrocytes obtained from Sprague Dawley rats were randomly divided into control, $\mathrm{A} \beta, \mathrm{GB}$ and $\mathrm{GB}+$ compound $\mathrm{C}$ groups. Cell viability and apoptosis were analyzed using Cell Counting Kit-8 and flow cytometry assays, respectively. Protein and mRNA expression levels were analyzed using western blotting and reverse transcription-quantitative PCR, respectively. The levels of superoxide dismutase (SOD), malondialdehyde (MDA), glutathione peroxidase (GSH-Px), reactive oxygen species (ROS) and ATP were determined using the corresponding commercial kits. The findings revealed that $G B$ attenuated $A \beta_{1-42}$-induced apoptosis and the $5^{\prime}$ adenosine monophosphate- activated protein kinase (AMPK) inhibitor compound $\mathrm{C}$ reversed the protective effects of GB. In addition, GB reversed $A \beta_{1-42}$-induced oxidative damage and energy metabolism disorders, including decreases in the levels of SOD, GSH-Px and ATP and increased the
\end{abstract}

Correspondence to: Professor Wei Xiao, Jiangsu Kanion Pharmaceutical Co. Ltd., 58 Kangyuan Road, Lianyungang, Jiangsu 222000, P.R. China

E-mail: xw_kanion@163.com

Professor Jingbo Zhu, School of Food Science and Technology, Dalian Polytechnic University, 1 Chigong Yuan, Dalian, Liaoning 116034, P.R. China

E-mail: zhujbdlgy@163.com

Key words: ginkgolide B, astrocytes, $\beta$ - amyloid $_{1-42}$, endoplasmic reticulum stress, oxidative stress, energy metabolism disorder, 5 ' adenosine monophosphate-activated protein kinase, Alzheimer's disease levels of MDA and ROS in astrocytes, while compound C reversed the anti-oxidative effect and the involvement of GB in maintaining energy metabolism in astrocytes. Finally, GB decreased the expression levels of the endoplasmic reticulum stress (ERS) proteins and the apoptotic protein CHOP and increased both mRNA and protein expression of the components of the energy metabolism-related AMPK/peroxisome proliferator-activated receptor $\gamma$ coactivator $1 \alpha /$ peroxisome proliferator-activated receptor $\alpha$ and anti-oxidation-related nuclear respiratory factor $2 /$ heme oxygenase $1 / \mathrm{NAD}(\mathrm{P}) \mathrm{H}$ dehydrogenase (quinone 1) pathways and downregulated the expression of $\beta$-secretase 1 . However, compound $\mathrm{C}$ could antagonize these effects. In conclusion, the findings demonstrated that GB protected against $A \beta_{1-42}$-induced apoptosis by inhibiting ERS, oxidative stress, energy metabolism disorders and $A \beta_{1-42}$ production probably by activating AMPK signaling pathways. The findings provided an innovative insight into the treatment using GB as a therapeutic in $A \beta_{1-42}$-related AD.

\section{Introduction}

Ginkgolide B (GB) is one of the main components of the extracts of Ginkgo biloba leaves and the pharmacodynamic component with the strongest activity and the highest specificity of the Ginkgo diterpenoid lactones (1). GB has been found to possess notable effects on the central nervous system, such as improving the cognitive function of patients with Alzheimer's disease (AD) and promoting the neuroprotective effects on acute hypoxic/ischemic injury $(2,3)$. The high purity of GB enables it to pass through the blood-brain barrier and be easily absorbed, which is beneficial in the treatment of neurodegenerative diseases $(4,5)$, including $\mathrm{AD}$, which is a destructive central nervous system lesion characterized by declining learning, memory loss and cognitive dysfunction (6,7). At present, the pathogenesis of AD remains to be elucidated, but it is well known that the abnormal metabolism and deposition of $\beta$-amyloid $(A \beta)$ in the brain tissues contribute to AD (8). Activated astrocytes are found around $A \beta$ deposition $(9,10)$ and are the most abundant type of cells in the central nervous system. A previous study indicates that astrocytes induce $A \beta$ degradation and clearance and the degradation of $A \beta$ mediated 
by astrocytes is impeded in the early stage of AD (11). Thus, astrocytes have regulatory roles in the onset of AD (12). GB has been found to have clinical effects on neuroprotection (13), but the protective effect of GB on astrocytes in AD and its potential molecular mechanism remain to be elucidated.

$\mathrm{A} \beta$ is the main factor leading to $\mathrm{AD}$ cognitive dysfunction and neurodegeneration because the excessive generation and aggregation of $A \beta$ results in a series of pathological and physiological changes, including endoplasmic reticulum (ER) stress (ERS), oxidative stress (OS), inflammatory response, energy metabolism disorder, tau hyperphosphorylation, synaptic degeneration, cell dysfunction and even apoptosis, causing abnormal learning, memory, cognition and behavior $(14,15)$. The aforementioned pathological processes interact with each other, stimulating the onset and progression of AD.

ER, which takes part in protein synthesis, post-translational modification and correct folding of proteins, is necessary to maintain the normal function of cells (16). ER dysfunction or loss of integrity causes ERS, which is key to neurodegenerative diseases $(17,18)$. Previous studies on patients with AD and the brain tissues of animal models demonstrate that $A \beta$ seriously disturbs the functions of ER, leading to excessive generation of $A \beta$, ERS activation $(19,20)$ and finally cell dysfunction and apoptosis (21). A previous study showed that mitochondrial damage was important in the pathogenesis of AD because mitochondria supplied energy, exchanged information, antagonized OS and provided energy for various cellular activities (22). The overaggregation of $A \beta$ influences the energy metabolism of mitochondria, decreases the generation of ATP and produces numerous oxygen radicals in the mitochondria to weaken the ability of cells to provoke oxidation and cause OS (23), resulting in apoptosis (24). Meanwhile, oxides and lipid peroxides increase the levels of the key amylase $\beta$ secretase 1 (BACE1) to cause the excessive generation of $A \beta(25)$. The two interact with each other to cause malignancy, mitochondrial dysfunction and serious oxidative injury, thus exacerbating the toxic responses of $A \beta$ (26). Astrocytes are important in neurodegenerative diseases and preventing the abnormal changes in astrocytes may help treat the diseases $(27,28)$. Therefore, the following hypothesis was proposed in the present study: GB might antagonize the neurotoxicity of $A \beta$, prevent ERS and OS, protect the normal metabolism of astrocytes and interrupt the excessive generation of $A \beta$, thus protecting astrocytes and preventing the progression of $\mathrm{AD}$.

\section{Materials and methods}

Reagents. GB was purchased from National Institutes for Food and Drug Control China, with $98 \%$ purity ascertained by high-performance liquid chromatography. A $\beta$ peptide fragments $\left(\mathrm{A} \beta_{1-42}\right.$; cat. no. SCP0038) was purchased from Sigma-Aldrich (Merck KGaA). Cell counting kit 8 (CCK-8; cat. no. C0039), annexin V-FITC apoptosis detection kit (cat. no. C1062), total superoxide dismutase assay kit (SOD; cat. no. S0109), lipid peroxidation malondialdehyde assay kit (MDA; cat. no. S0131), glutathione peroxidase assay kit (GSH-Px; cat. no. S0056), reactive oxygen species assay kit (ROS; cat. no. S0033), ATP assay kit (cat. no. S0131S), IgG horseradish peroxidase (HRP)-conjugated secondary antibodies (cat. no. A0208; 1:10,000), BCA Protein Assay kit (cat. no. P0012S) and BSA (cat. no. ST023) were purchased from Beyotime Institute of Biotechnology. Minibest universal RNA extraction kit (cat. no. 9767), PrimeScript ${ }^{\mathrm{TM}}$ RT reagent kit with gDNA eraser (perfect real time; cat. no. RR047) and TB Green ${ }^{\circledR}$ Premix Ex Taq ${ }^{\mathrm{TM}}$ (Tli RNase H Plus; cat. no. RR420) were purchased from Takara Bio Inc. DMEM/F12 medium (cat. no. C11330500BT) and fetal bovine serum (cat. no. 10099141C) were purchased from Gibco (Thermo Fisher Scientific, Inc.). Clarity Western ECL substrate was purchased from Bio-Rad Laboratories, Inc. Compound $\mathrm{C}$, antibodies against $\beta$-actin (cat. no. 4970; rabbit; 1:1,000), $\beta$-secretase (BACE1; cat. no. 5606; rabbit; 1:1,000), $\beta$-tubulin (cat. no. 6181; rabbit; 1:1,000), protein kinase RNA-like endoplasmic reticulum kinase (PERK; Phospho Thr980; cat. no. 3179; rabbit; 1:1,000), PERK (cat. no. 3192; rabbit; 1:1,000), eukaryotic translation initiation factor 2 subunit $\alpha$ (eIF2 $\alpha$; PhosphoSer51; cat. no. 5199; rabbit; 1:1,000), eIF2 $\alpha$ (cat. no. 9079; rabbit; 1:1,000), 5' adenosine monophosphate-activated protein kinase (AMPK; Phospho Thr172; cat. no. 2531; rabbit; 1:1,000), AMPK (cat. no. 2532; rabbit; 1:1,000), heme oxygenase 1 (HO-1; cat. no. 82206; rabbit; 1:1,000) were purchased from Cell Signaling Technology, Inc., inositol-requiring enzyme $1 \alpha$ (IRE1 $\alpha$; cat. no. 37073; rabbit; 1:1,000), proliferator-activated receptor $\gamma$ coactivator $1 \alpha$ (PGC-1 $\alpha$; cat. no. 54481; rabbit; 1:1,000), C/EBP-homologous protein (CHOP; cat. no. 179823; rabbit; 1:1,000), $78 \mathrm{kDa}$ glucose-regulated protein (GRP78; cat. no. 108613; rabbit; 1:1,000), activating transcription factor 6 (ATF6; cat. no. 203119; rabbit; 1:1,000), nuclear factor erythroid 2-related factor 2 (Nrf2; cat. no. 137550; rabbit; 1:1,000), $\mathrm{NAD}(\mathrm{P}) \mathrm{H}$ dehydrogenase (quinone 1) (NQO1; cat. no. 28947; rabbit; $1: 1,000)$ and peroxisome proliferator-activated receptor $\alpha$ (PPAR $\alpha$; cat. no. 215270; rabbit; 1:1,000) were obtained from Abcam. All primers were purchased from Sangon Biotech Co., Ltd.

Animals. A total of 3 pregnant Sprague Dawley (SD) rats (age, 2 months; 2-3 weeks pregnancy; weight, 260-270 g) were purchased from Experimental Animal Center, Yangzhou University (Yangzhou, China). The rats were accommodated in an animal room with a 12-h light/dark cycle and ad libitum access to food and water at a temperature and humidity of $22 \pm 1^{\circ} \mathrm{C}$ and $50 \pm 10 \%$, respectively. The pregnant rats were fed with basic diet until postpartum. All experiments were carried out following the guidelines and protocols approved by the Ethics Committee for the Use of Experimental Animals of Jiangsu Kanion Pharmaceutical Co. Ltd. and the State Key Laboratory of New Pharmaceutical Process for Traditional Chinese Medicine (Lianyungang, China; approval no. 2019012). The 1-2-day-old rats and postpartum SD rats were sacrifice with $5 \%$ isoflurane, followed by cervical dislocation for the confirmation of mortality.

Astrocyte cultures. The cerebral cortices of 1-2-day-old rats were digested in $0.25 \%$ trypsin solution at $37^{\circ} \mathrm{C}$ for $30 \mathrm{~min}$ and the same volume of DMEM/F12 containing $10 \%$ fetal bovine serum was added to stop digestion. The cortices were repeatedly blown with a straw until the tissue mass disappeared completely and the liquid was turbid. The suspension was filtered through a 200-mesh sterile screen and the filtrate 
was collected and centrifuged $(300 \mathrm{x} \mathrm{g})$ for $5 \mathrm{~min}$ at $20-25^{\circ} \mathrm{C}$. The cells were then resuspended in DMEM/F12 [10\% (v/v) fetal bovine serum] and incubated at $37^{\circ} \mathrm{C}$ in the presence of $5 \% \mathrm{CO}_{2}$ and $90 \%$ relative humidity. At $90 \%$ confluence of the cells, microglial cells and oligodendrocytes were removed from astrocyte cultures by shaking (200 rpm) overnight at $37^{\circ} \mathrm{C}(29)$.

Glial fibrillary acidic protein (GFAP) is a marker of astrocytes, which can be identified by GFAP immunofluorescence staining. The identification of purified astrocytes is presented in Fig. S1 (magnification, x100). Following staining with GFAP, green fluorescence was exhibited under a fluorescence microscope. Following staining with DAPI, blue fluorescence was exhibited under a fluorescence microscope. The cell morphology after fused cells stained by GFAP or DAPI and the purity of astrocytes were $>95 \%$ (Fig. S1). Astrocytes with purity $>95 \%$ were used in subsequent experiments.

Drug treatments. The optimal concentration and time of action of $\mathrm{GB}$ and $\mathrm{A} \beta_{1-42}$ were determined based on a previous study (30) and the pre-experimental results of their influence on astrocyte activity (Fig. S2). As demonstrated in Fig. S2, the cells treated with a concentration of $10 \mu \mathrm{M} \mathrm{A} \beta_{1-42}$ in DMEM/F12 for $24 \mathrm{~h}$ as an $\mathrm{A} \beta_{1-42}$-damage model and the cell vitality treated with the concentration of 20 and $40 \mu \mathrm{M} \mathrm{GB}$ in DMEM/F12 for $24 \mathrm{~h}$ showed no difference compared with the normal group although the cell activity was significantly improved in $80 \mu \mathrm{M}$ GB. In addition, the cell viability of 100 and $200 \mu \mathrm{M}$ GB groups was lower compared with the 20, 40 and $80 \mu \mathrm{M}$ GB groups. The concentration of compound $\mathrm{C}$, an effective and reversible AMPK inhibitor, was determined based on the protein expression of AMPK, as demonstrated in Fig. S2. The preliminary results showed that $10 \mu \mathrm{M}$ compound C in DMEM/F12 for $24 \mathrm{~h}$ inhibited AMPK phosphorylation compared with the normal group.

Subsequently, $24 \mathrm{~h}$ after of seeding, the medium was replaced by a fresh medium containing the drugs. The astrocytes were randomly divided into the following groups: Control (without any treatment in DMEM/F12), A $\beta$ (treated with the final concentration of $10 \mu \mathrm{M} \mathrm{A} \beta_{1-42}$ in DMEM/F12 for $24 \mathrm{~h}$ ), GB (treated with the final concentration of $10 \mu \mathrm{M}$ $\mathrm{A} \beta_{1-42}$ and 20,40 or $80 \mu \mathrm{M}$ GB in DMEM/F12 for $24 \mathrm{~h}$ ) and $80 \mu \mathrm{M} \mathrm{GB}+$ compound $\mathrm{C}$ (treated with the final concentration of $10 \mu \mathrm{M} \mathrm{A} \beta_{1-42}, 80 \mu \mathrm{M}$ GB and $10 \mu \mathrm{M}$ compound $\mathrm{C}$ in DMEM/F12 for $24 \mathrm{~h}$ ).

$C C K-8$ assay. The cell viability was evaluated using the CCK- 8 assay. In brief, $100 \mu 1$ of astrocytes were plated into 96 -well plates $\left(1 \times 10^{4}\right.$ cells per well) and treated by groups, with three repeats per group. Then, $10 \mu \mathrm{l}$ of CCK- 8 solution was added to each well and the plate was further incubated at $37^{\circ} \mathrm{C}$ for $2 \mathrm{~h}$. The optical density at $450 \mathrm{~nm}$ was determined using a microplate reader (Molecular Devices, LLC).

Annexin V/PI assay. The early and late apoptosis of astrocytes was detected by flow cytometry. Astrocytes $(\sim 2 \mathrm{ml})$ at the concentration of $1 \times 10^{5} / \mathrm{ml}$ were seeded into 6 -well plates and treated by groups. Then, the astrocytes were washed twice with PBS, digested with $0.25 \%$ trypsin without EDTA, collected in the centrifuge tube, centrifuged $(300 \mathrm{xg})$ for $5 \mathrm{~min}$ at $20-25^{\circ} \mathrm{C}$, and washed three times with PBS. The supernatant was discarded and $195 \mu \mathrm{l}$ of the binding buffer was added to resuspend the astrocytes. Subsequently, $5 \mu 1$ of Annexin V/FITC and $10 \mu \mathrm{l}$ of PI were added to the astrocytes in the dark, followed by detection using flow cytometry (ACEA NovoCyte; ACEA Bioscience, Inc.; Agilent Technologies, Inc.) and NovoExpress 1.2.1 software (ACEA Biosciences, Inc.; Agilent Technologies, Inc.). SOD, MDA, GSH-Px, ROS and ATP assay. The cells were collected, washed once or twice with PBS, precipitated, resuspended, and mixed with PBS. They were ruptured ultrasonically, and the homogenate was used for determining the SOD and GSH-Px activities and MDA, ROS and ATP content using commercially available kits (SOD assay kit with NBT; GSH-Px assay kit, colorimetric method; MDA assay kit, thiobarbituric acid method; ROS assay kit with DCFH-DA; and ATP assay kit, respectively) following the manufacturer's protocols.

RNA extraction and reverse transcription-quantitative $(R T-q) P C R$. In total, $2 \mathrm{ml}$ suspension containing astrocytes $\left(1 \times 10^{5} \mathrm{cell} / \mathrm{ml}\right)$ was inoculated into the 6 -well plates and treated with the indicated treatments, with three replicates per treatment. Total RNA was extracted from cells using the Minibest universal RNA extraction kit, followed by reverse transcription to synthesize cDNA using PrimeScript RT Master Mix. The reverse transcription was conducted at $37^{\circ} \mathrm{C}$ for $15 \mathrm{~min}$ and $85^{\circ} \mathrm{C}$ for $5 \mathrm{sec}$. According to the manufacturer's protocols, the gene transcripts were quantified using the RT-qPCR reaction system $(20 \mu 1)$ with TB Green and PCR was carried out under the following conditions: Initial denaturation at $95^{\circ} \mathrm{C}$ for $10 \mathrm{~min}$; followed by 40 cycles of $95^{\circ} \mathrm{C}$ for $30 \mathrm{sec}, 60^{\circ} \mathrm{C}$ for $30 \mathrm{sec}$ and $95^{\circ} \mathrm{C}$ for $15 \mathrm{sec}$; and a final extension at $60^{\circ} \mathrm{C}$ for $1 \mathrm{~min}$. The following primer pairs were used for qPCR: ACTB forward, 5'-TGTCACCAACTG GGACGATA-3' and ACTB reverse, 5'-GGGGTGTTGAAG GTCTCAAA-3'; CHOP forward, 5'-CCTCGCTCTCCAGAT TCCAGTCAG- 3' and CHOP reverse, 5'-TCTCCTGCTCCT TCTCCTTCATGC-3'; Nrf2 forward, 5'-TGACTCCGGCAT TTCACTGA-3' and Nrf2 reverse, 5'-GTGGGTCTCCGTAAA TGGAAGA-3'; HO-1 forward, 5'-TATCGTGCTCGCATG AACACTCTG-3' and HO-1 reverse, 5'-GTTGAGCAGGAA GGCGGTCTTAG-3'; NQO1 forward, 5'-AGAAGCGTCTGG AGACTGTCTGG-3' and NQO1 reverse, 5'-GATCTGGTT GTCGGCTGGAATGG-3'; AMPK forward, 5'-ATGATG AGGTGGTGGAGCAGAGG-3' and AMPK reverse, 5'-GTT CTCGGCTGTGCTGGAATCG-3'; PGC1 $\alpha$ forward, 5'-TTG AAGAGCGCCGTGTGAT-3' and PGC1 $\alpha$ reverse, 5'-AAA AACTTCAAAGCGGTCTCTCA-3'; PPAR $\alpha$ forward, 5'-TGA CTTGGCCATATTTATAGCTGTCA-3' and PPAR $\alpha$ reverse, 5'-GATGTCCTCGATGGGCTTCA-3'. All RT-qPCR experiments were repeated three times and the relative expression levels were quantified using the $2^{-\Delta \Delta \mathrm{Cq}}$ method (31).

Western blotting. The total protein was extracted from astrocytes with ice-cold RIPA buffer and the protein content was estimated using a BCA protein assay kit. The total protein $(30 \mu \mathrm{g})$ was separated by $10 \%$ sodium dodecyl sulfate-polyacrylamide gel electrophoresis and electrotransferred onto a polyvinylidene fluoride membrane for $2 \mathrm{~h}$ in an ice-cold buffer. The membranes were blocked in 5\% BSA for $1 \mathrm{~h}$ 
at room temperature, incubated overnight at $4{ }^{\circ} \mathrm{C}$ with the corresponding primary antibodies, washed, incubated with horse radish peroxidase-conjugated secondary antibody for $1 \mathrm{~h}$ at room temperature and developed using an enhanced chemiluminescence kit. Gray-scale scanning and quantification were performed using Image Lab 3.0 software (Bio-Rad Laboratories, Inc.).

Statistical analysis. All data were presented as mean \pm standard deviation from $\geq 3$ independent experiments. Statistical analysis permitted normalization of the $2^{-\Delta \Delta C q}$ of RT-qPCR and the value of protein gray of western blotting in the $A \beta$ group and the cell activity of CCK8 in control group. Statistical analyses were performed by one-way ANOVA test evaluating significant differences between treatments using SPSS v17.0 statistical software (SPSS, Inc.). The comparison between the two groups was conducted by LSD method with homogeneous variances and Tamhane method with inhomogeneous variances. $\mathrm{P}<0.05$ was considered to indicate a statistically significant difference.

\section{Results}

Effect of $G B$ on $A \beta_{1-42}$-induced cell viability in astrocytes. The activity of astrocytes is demonstrated in Fig. 1A. The activity of astrocytes clearly decreased in the $\mathrm{A} \beta$ group compared with the control group $(\mathrm{P}<0.01)$, while the activity was higher in the 20, 40 and $80 \mu \mathrm{M}$ GB groups compared with the $\mathrm{A} \beta$ group in a concentration-dependent manner $(\mathrm{P}<0.05 ; \mathrm{P}<0.01)$. However, the cell viability was significantly lower in the $80 \mu \mathrm{M}$ GB + compound $\mathrm{C}$ group compared with the $80 \mu \mathrm{M}$ GB group $(\mathrm{P}<0.01)$. The results demonstrated that $\mathrm{A} \beta_{1-42}$ decreased astrocyte viability and caused cellular damage, while GB enhanced astrocyte viability and protected the cells. In addition, the effects of GB on $A \beta_{1-42}$-induced decreased astrocyte viability were inhibited by the AMPK inhibitor compound C.

Effect of $G B$ on $A \beta_{1-42}$-induced cell apoptosis in astrocytes. Apoptosis detection was performed on each group of astrocytes using flow cytometry and the results are demonstrated in Fig. $1 \mathrm{~B}$ and $\mathrm{C}$. Compared with the control group, $\mathrm{A} \beta_{1-42}$ treatment clearly increased the apoptotic rate of astrocytes $(\mathrm{P}<0.01)$. The number of apoptotic astrocytes was significantly lower in the 20,40 and $80 \mu \mathrm{M}$ GB groups than in the $\mathrm{A} \beta$ group $(\mathrm{P}<0.05, \mathrm{P}<0.01)$, while the apoptotic rate was significantly higher in the $80 \mu \mathrm{M} \mathrm{GB}+$ compound $\mathrm{C}$ group than in the $80 \mu \mathrm{M}$ GB group $(\mathrm{P}<0.01)$. Hence, GB effectively reduced the $\mathrm{A} \beta_{1-42}$-induced apoptosis of astrocytes and compound $\mathrm{C}$ inhibited this effect.

Effect of $G B$ on $A \beta_{1-42}$-induced OS-related factors in astrocytes. As demonstrated in Fig. $2 \mathrm{~A}-\mathrm{D}, \mathrm{A} \beta_{1-42}$ clearly decreased the activities of SOD and GSH-Px and distinctly increased the MDA content and ROS levels in astrocytes compared with the control group $(\mathrm{P}<0.05 ; \mathrm{P}<0.01)$. The activities of $\mathrm{SOD}$ and GSH-Px visibly increased $(\mathrm{P}<0.01)$ while the MDA content and ROS levels significantly decreased $(\mathrm{P}<0.05, \mathrm{P}<0.01)$ in the 40 and $80 \mu \mathrm{M}$ GB groups compared with the $\mathrm{A} \beta$ group. The activities of SOD and GSH-Px significantly decreased $(\mathrm{P}<0.05$; $\mathrm{P}<0.01)$ and the MDA content and ROS level significantly increased $(\mathrm{P}<0.05 ; \mathrm{P}<0.01)$ in the $80 \mu \mathrm{M}$ GB + compound $\mathrm{C}$ group compared with the $80 \mu \mathrm{M}$ GB group. Thus, the results showed that GB could attenuate the $A \beta_{1-42}$-induced decrease in antioxidants in astrocytes; however, compound $\mathrm{C}$ could provoke this effect.

Effect of $G B$ on $A \beta_{1-42}$-induced levels of ATP in astrocytes. As demonstrated in Fig. $2 \mathrm{E}, \mathrm{A} \beta_{1-42}$ clearly decreased the content of ATP in astrocytes compared with the control group $(\mathrm{P}<0.01)$, whereas the content of ATP significantly increased $(\mathrm{P}<0.01)$ following $80 \mu \mathrm{M}$ GB treatment compared with the $\mathrm{A} \beta$ treatment. However, the content of ATP was significantly lower in the $80 \mu \mathrm{M}$ GB + compound $\mathrm{C}$ group compared with the $80 \mu \mathrm{M}$ GB group $(\mathrm{P}<0.01)$. Thus, GB could enhance the ATP level of astrocytes following treatment with $A \beta_{1-42}$ and compound $\mathrm{C}$ could prevent this effect.

Effect of GB on expressions of ERS signal molecule in astrocytes. The data presented in Fig. 3A and B indicate that the protein expression levels of CHOP, GRP78, phosphorylated (p)-PERK, p-eIf $2 \alpha$ and ATF6 significantly increased in the $\mathrm{A} \beta$ group compared with the control group $(\mathrm{P}<0.05, \mathrm{P}<0.01)$. In addition, 20, 40 and $80 \mu \mathrm{M}$ GB notably repressed the upregulation of CHOP, GRP78 and p-PERK; 40 and $80 \mu \mathrm{M}$ GB significantly inhibited the upregulation of p-eIf $2 \alpha$ and IRE1 $\alpha$; and 20 and $80 \mu \mathrm{M}$ GB notably repressed the upregulation of ATF6 $(\mathrm{P}<0.05 ; \mathrm{P}<0.01)$ compared with $\mathrm{A} \beta$ alone. However, $80 \mu \mathrm{M}$ GB + compound $\mathrm{C}$ treatment significantly increased the protein expression levels of CHOP and ERS marker proteins $(\mathrm{P}<0.05 ; \mathrm{P}<0.01)$ compared with $80 \mu \mathrm{M}$ GB treatment (Fig. 4A and $\mathrm{B}$ ). The experimental results proved that GB protected astrocytes from $A \beta_{1-42}$-induced apoptosis via inhibiting ERS, while AMPK inhibitor compound $C$ could prevent this effect. Therefore, the mechanism of GB inhibiting ERS may be closely related to the AMPK signaling pathway.

Effect of $G B$ on the expression of related proteins and genes by Nrf 2 pathway. As demonstrated in Fig. 5A and B, the protein expression levels of Nrf2 and NQO1 were significantly lower in the $A \beta$ group compared with the control group $(\mathrm{P}<0.05)$. However, the expression levels of $\mathrm{Nrf} 2$ and $\mathrm{HO}-1$ proteins in the $80 \mu \mathrm{M}$ GB group and the levels of NQO1 protein in the 20, 40 and $80 \mu \mathrm{M}$ GB groups were significantly higher compared with the $\mathrm{A} \beta$ group $(\mathrm{P}<0.05)$. As demonstrated in Fig. 6, the expression levels of Nrf2, HO-1 and NQO1 genes were significantly higher in the 40 and $80 \mu \mathrm{M}$ GB groups compared with the $\mathrm{A} \beta$ group $(\mathrm{P}<0.05 ; \mathrm{P}<0.01)$. However, the mRNA and protein expression levels of Nrf2, HO-1 and NQO1 were significantly lower in the $80 \mu \mathrm{M} \mathrm{GB}+$ compound $\mathrm{C}$ group compared with the $80 \mu \mathrm{M}$ GB group $(\mathrm{P}<0.05$; Figs. 6 and 7A and B). The results indicated that GB could reduce $A \beta_{1-42}$-induced OS by activating the Nrf2-HO-1-NQO1 pathway, while compound $\mathrm{C}$ prevented this effect. Therefore, the mechanism of GB inhibiting OS may be closely related to the AMPK signaling pathway.

Effect of $G B$ on the expression of related genes and proteins by $A M P K$ pathway. As demonstrated in Fig. $8 \mathrm{~A}$ and $\mathrm{B}, \mathrm{A} \beta_{1-42}$ clearly decreased the protein expression levels of $\mathrm{p}$-AMPK and PPAR $\alpha$ and increased the expression level of BACE1 protein 
A

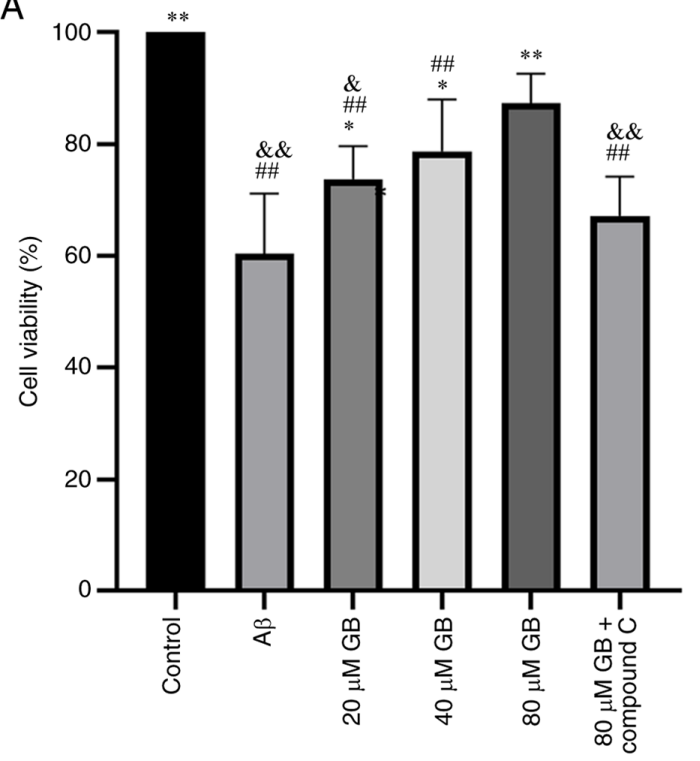

B

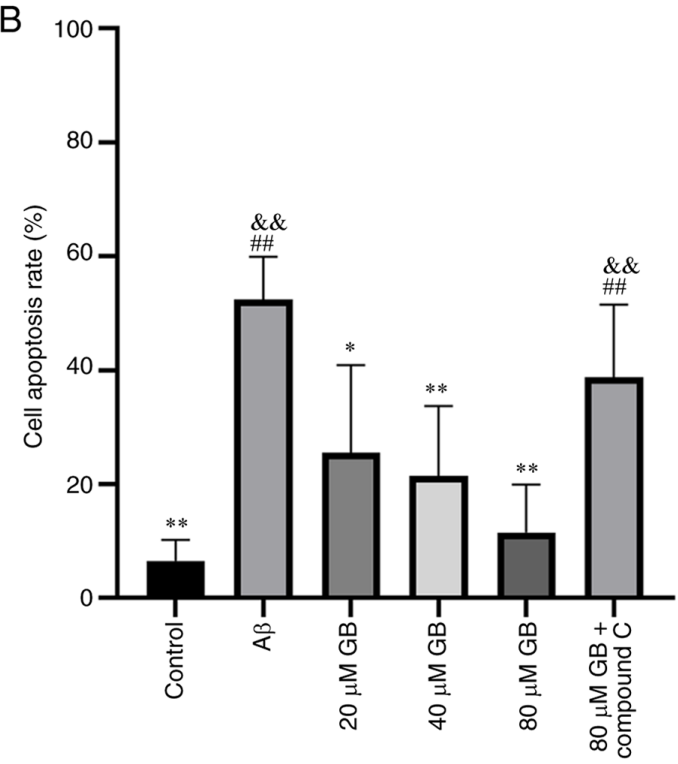

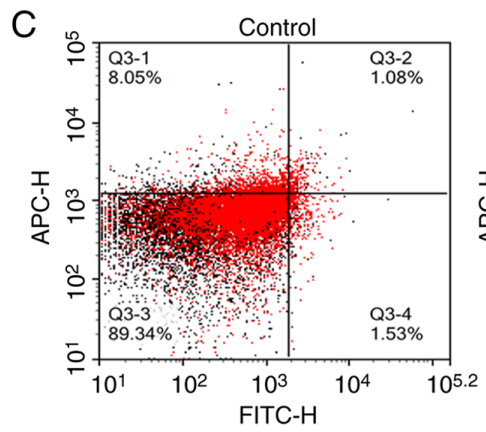
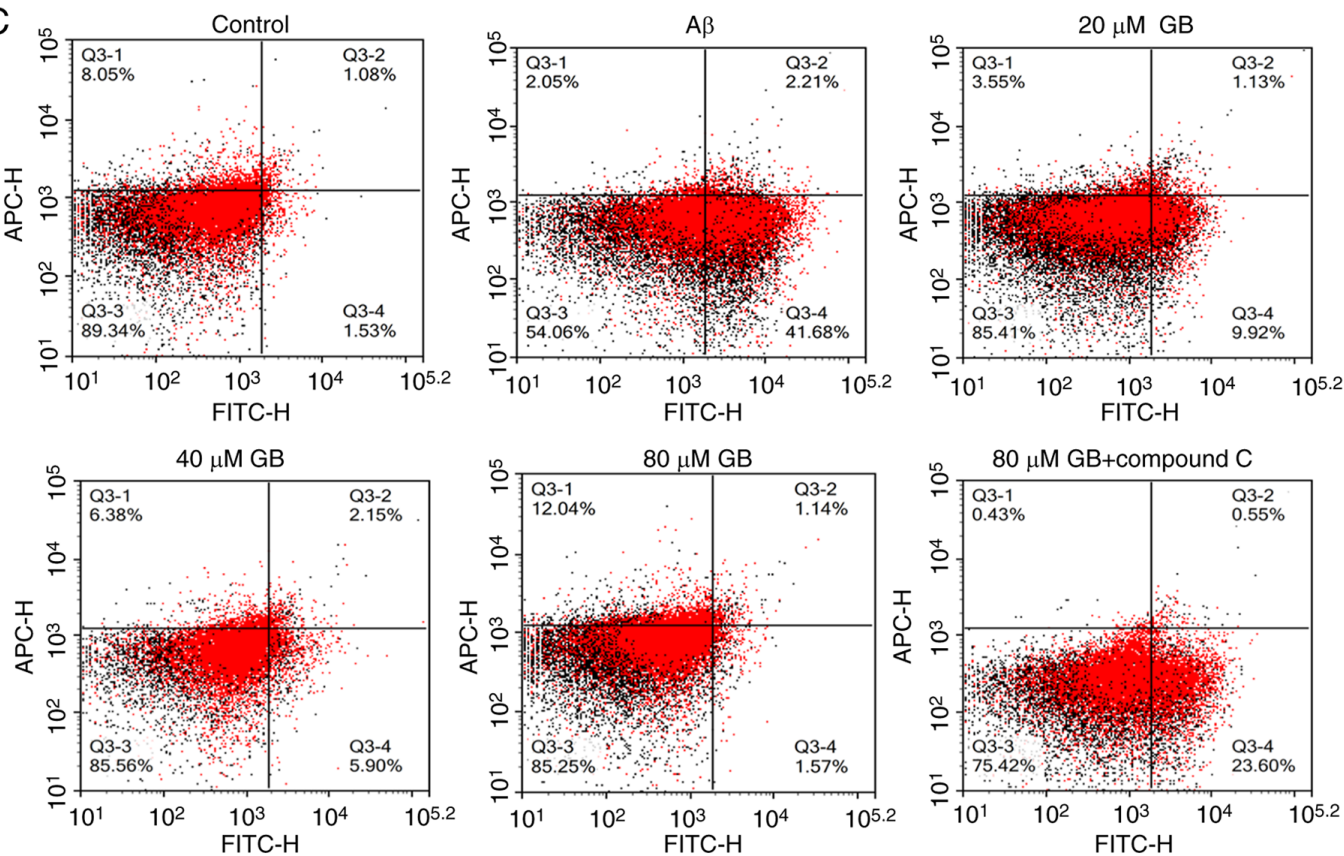

Figure 1. Effect of GB on cell viability and apoptosis are affected by $A \beta_{1-42}$ in astrocytes. (A) Astrocyte viability was detected using CCK-8 assay. (B and C) Apoptosis detection was performed on each group of astrocytes by flow cytometry. All the astrocytes were randomly divided into control group (without any treatment in DMEM/F12), A $\beta$ group (treated with the final concentration of $10 \mu \mathrm{M} \mathrm{A} \beta_{1-42}$ in DMEM/F12 for 24 h), GB group (treated with the final concentration of $10 \mu \mathrm{M} \mathrm{A} \beta_{1-42}$ and 20,40 or $80 \mu \mathrm{M}$ GB in DMEM/F12 for $24 \mathrm{~h}$ ) and $80 \mu \mathrm{M} \mathrm{GB}+$ compound C group (treated with the final concentration of $10 \mu \mathrm{M} \mathrm{A} \beta_{1-42}, 80 \mu \mathrm{M}$ GB and $10 \mu \mathrm{M}$ compound $\mathrm{C}$ in DMEM/F12 for $\left.24 \mathrm{~h}\right) .{ }^{* \#} \mathrm{P}<0.01$ vs. control group, ${ }^{*} \mathrm{P}<0.05$ and ${ }^{* *} \mathrm{P}<0.01$ vs. $\mathrm{A} \beta$ group, ${ }^{\&} \mathrm{P}<0.05$ and \&\&P<0.01 vs. $80 \mu \mathrm{M}$ GB group. GB, ginkgolide $\mathrm{B} ; \mathrm{A} \beta, \beta$-amyloid.

compared with the control group $(\mathrm{P}<0.05 ; \mathrm{P}<0.01)$. In addition, the expression levels of p-AMPK, PGC1 $\alpha$ and PPAR $\alpha$ proteins in the 40 and $80 \mu \mathrm{M}$ GB groups and the expression level of PPAR $\alpha$ proteins in the $20 \mu \mathrm{M}$ GB group significantly increased $(\mathrm{P}<0.05 ; \mathrm{P}<0.01)$, while the expression level of BACE1 protein in the 40 and $80 \mu \mathrm{M}$ GB groups significantly decreased $(\mathrm{P}<0.05 ; \mathrm{P}<0.01)$. As demonstrated in Fig. 9, the expression level of the AMPK gene in astrocytes significantly decreased and the expression level of the BACE1 gene significantly increased after treatment with $\mathrm{A} \beta_{1-42}$ compared with that in the control group $(\mathrm{P}<0.05)$. In contrast, the gene and protein expression levels of p-AMPK/AMPK, PGC1 $\alpha$ and PPAR $\alpha$ were significantly lower and the gene and protein expression level of BACE1 were significantly higher in the $\mathrm{A} \beta$ and $80 \mu \mathrm{M}$ $\mathrm{GB}+$ compound $\mathrm{C}$ group compared with the $80 \mu \mathrm{M}$ GB group $(\mathrm{P}<0.05 ; \mathrm{P}<0.01$; Figs. $9,10 \mathrm{~A}$ and $\mathrm{B})$. The results showed that GB protected astrocytes from $A \beta_{1-42}$-induced apoptosis by regulating energy metabolism, while compound $\mathrm{C}$ could prevent this effect.

\section{Discussion}

The $A \beta$ protein cascade hypothesis remains the dominant theory of AD pathogenesis; it hypothesizes that the main 

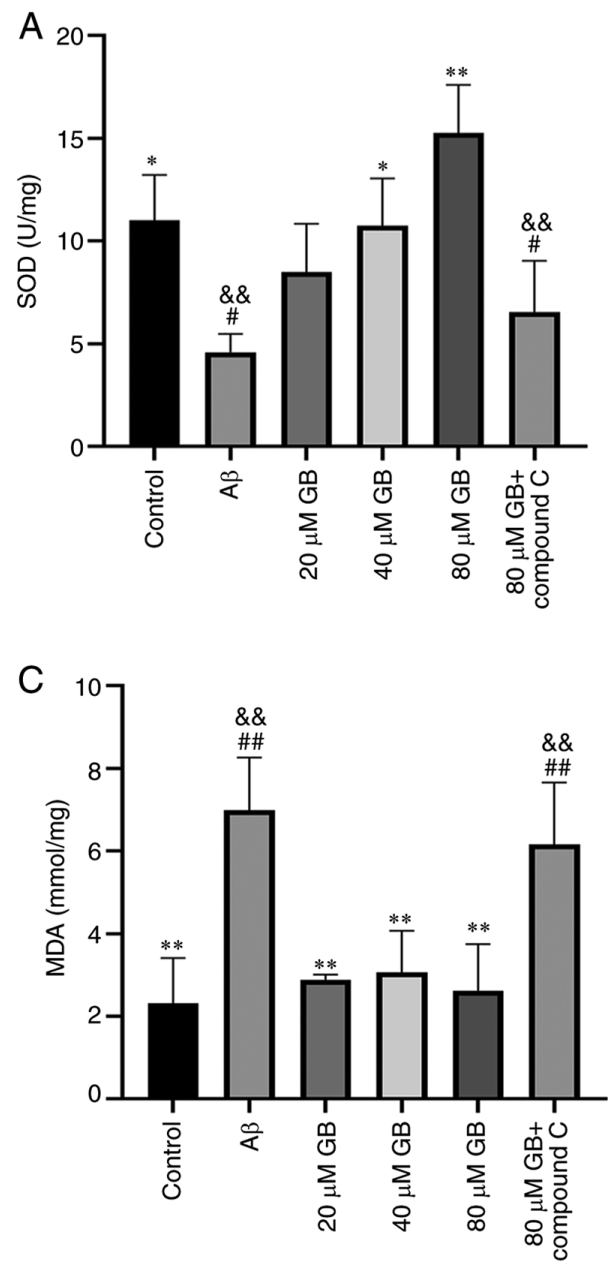

B
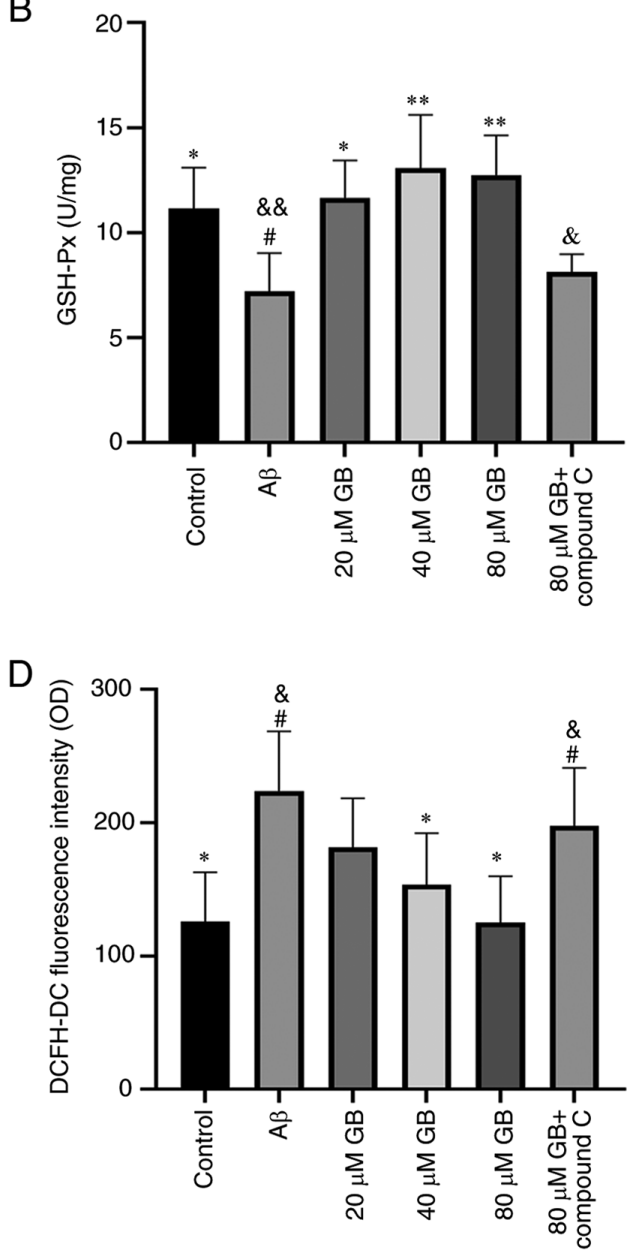

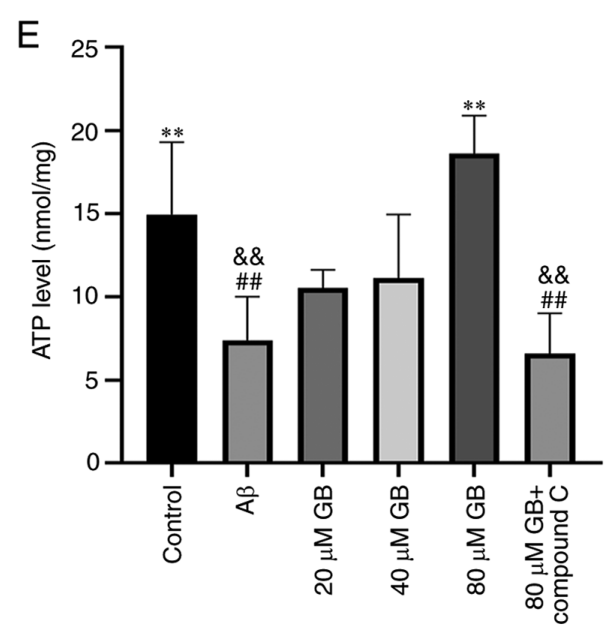

Figure 2. Effect of GB on $A \beta_{1-42}$-induced levels of OS-related factors and ATP in astrocytes. (A) GB increased the activity of SOD in A $\beta_{1-42}$ treated astrocytes and compound $\mathrm{C}$ decreased this effect. (B) GB increased the activity of GSH-Px in A $\beta_{1-42}$ treated astrocytes and compound C decreased this effect. (C) GB decreased the activity of MDA in $A \beta_{1-42}$ treated astrocytes and compound $\mathrm{C}$ decreased this effect. (D) GB decreased ROS level in A $\beta_{1-42}$ treated astrocytes and compound $\mathrm{C}$ decreased this effect. (E) GB increased the content of ATP in $A \beta_{1-42}$ treated astrocytes and compound $\mathrm{C}$ decreased this effect. ${ }^{\# P}<0.05$ and ${ }^{\# \#} \mathrm{P}<0.01$ vs. control group, ${ }^{*} \mathrm{P}<0.05$ and ${ }^{* * *} \mathrm{P}<0.01$ vs. $\mathrm{A} \beta$ group, ${ }^{\circledR} \mathrm{P}<0.05$ and ${ }^{\& \&} \mathrm{P}<0.01$ vs. $80 \mu \mathrm{M}$ GB group. GB, ginkgolide $\mathrm{B} ; \mathrm{A} \beta, \beta$-amyloid; SOD, superoxide dismutase; GSH-Px, glutathione peroxidase; MDA, malondialdehyde.

component of amyloid plaque $A \beta$ is excessively generated to cause neuronal death, synaptic loss, hyperphosphorylated tau protein and declining cognitive function $(32,33) . A \beta_{1-42}$ soluble oligomers are the major form in $\mathrm{A} \beta$ and they aggregate more easily and are more toxic. They surround necrotic synapses and activated astrocytes $(34,35)$, the major components of the central nervous system and closely related to the maintenance and normal operation of brain functions. The abnormal functions and degeneration of these synapses and activated astrocytes can induce neurodegenerative diseases. Physiologically, astrocytes can take up and internalize the $A \beta$ from cells and degrade them to protect neurons $(36,37)$. 

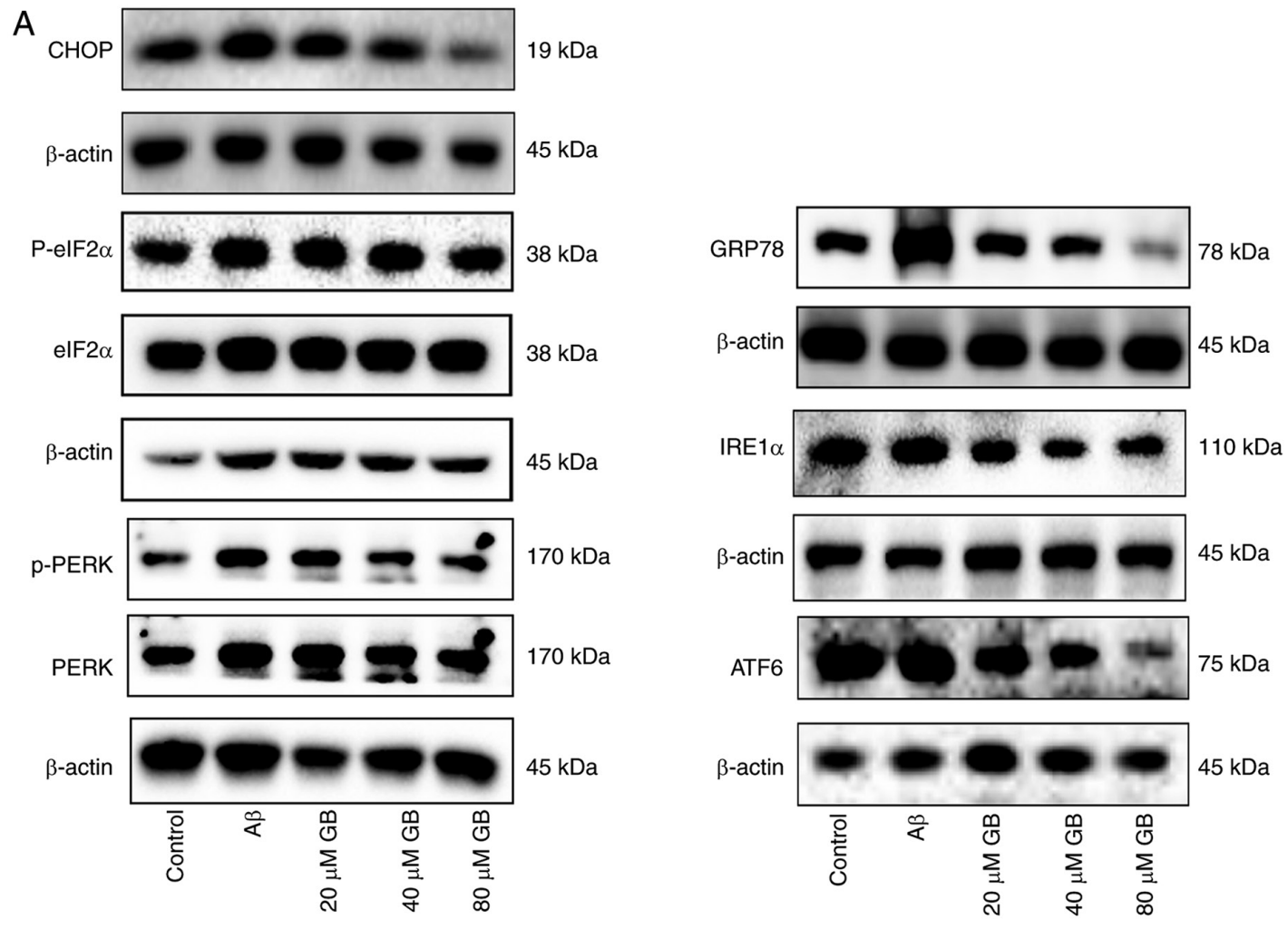

B

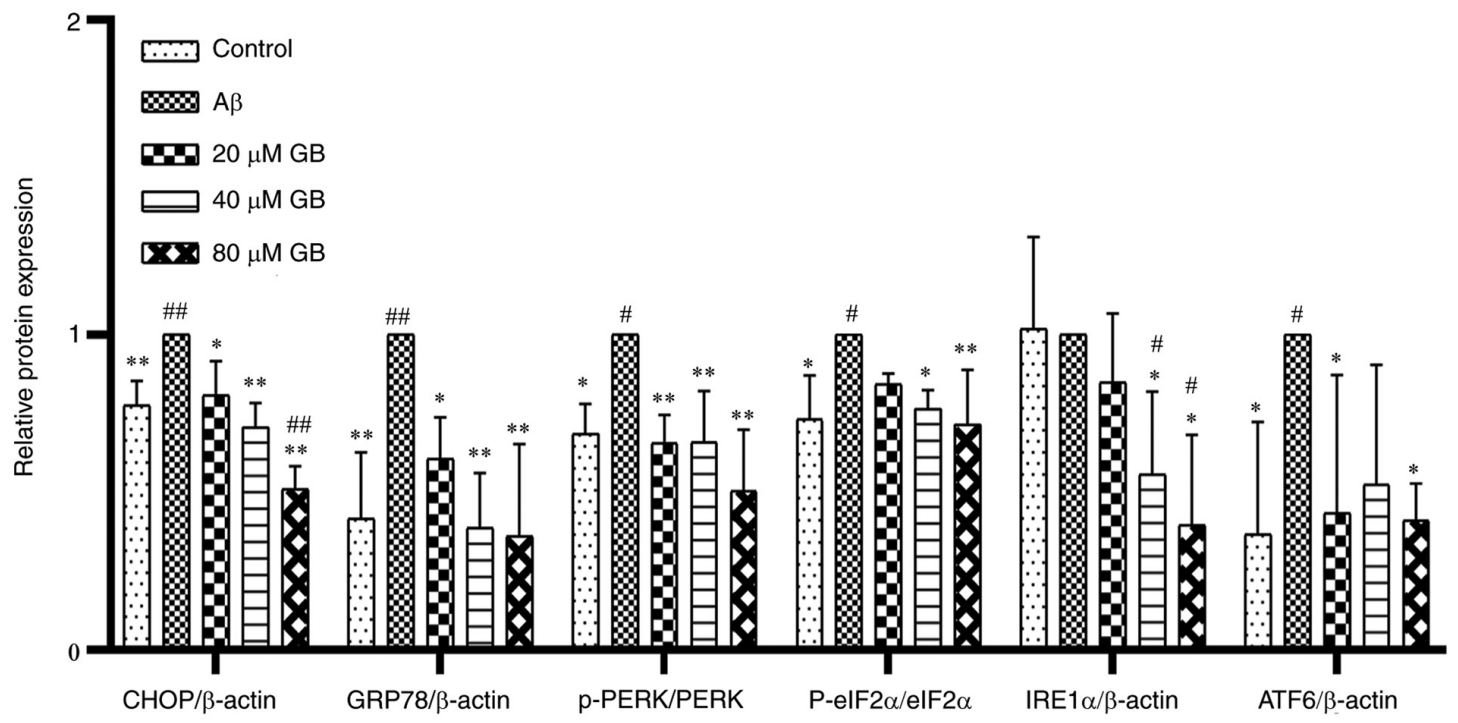

Figure 3. Effect of GB on expressions of ERS signal molecule in astrocytes. (A) Western blotting image and (B) western blotting data of protein expression levels of ERS following treatment with $10 \mu \mathrm{M} \mathrm{A} \beta_{1-42}$ with different GB concentration $(20,40$ and $80 \mu \mathrm{M} \mathrm{GB})$ or treated with $10 \mu \mathrm{M} \mathrm{A} \beta_{1-42}$ for $24 \mathrm{~h} .{ }^{*} \mathrm{P}<0.05$ and ${ }^{\# \#} \mathrm{P}<0.01$ vs. control group, ${ }^{*} \mathrm{P}<0.05$ and ${ }^{* *} \mathrm{P}<0.01$ vs. $\mathrm{A} \beta$ group. GB, ginkgolide $\mathrm{B}$; ERS, endoplasmic reticulum stress; $\mathrm{A} \beta, \beta$-amyloid; $\mathrm{p}$-, phosphorylated; GRP78, binding immunoglobulin protein; PERK, protein kinase R like endoplasmic reticulum kinase; eIF2 $\alpha$, eukaryotic translation initiation factor 2 subunit 1; eIF2 $\alpha$, inositol-requiring enzyme $1 \alpha$; ATF6, activating transcription factor 6.

However, pathologically, $A \beta$ causes the overactivation of astrocytes, leading to ERS, OS, inflammatory response, and finally apoptosis $(19,38)$. The present study found that $\mathrm{A} \beta_{1-42}(10 \mu \mathrm{M})$ caused astrocyte apoptosis and GB (20, 40 and $80 \mu \mathrm{M})$ relieved astrocyte apoptosis caused by $\mathrm{A} \beta_{1-42}$ effectively, implying that GB could protect astrocytes from $\mathrm{A} \beta_{1-42}$-induced apoptosis.

In the progression of $\mathrm{AD}$, the examination of brain tissues of patients with $\mathrm{AD}$ and animal models has demonstrated that
ERS has some association with the toxicity of $\mathrm{A} \beta(17,20)$, thereby disturbing the functions of ER and leading to the overactivation of ERS in neural cells (19) and deposition of $A \beta$. In addition, $A \beta$ and hyperphosphorylated tau protein interact with each other and move into blood circulation, aggravating the condition of patients with AD $(39,40)$. Moderate ERS can protect and recover homeostasis but long-standing ERS induces apoptosis. That is to say excessive ERS results in apoptosis through CHOP (41). In the present study experiments 

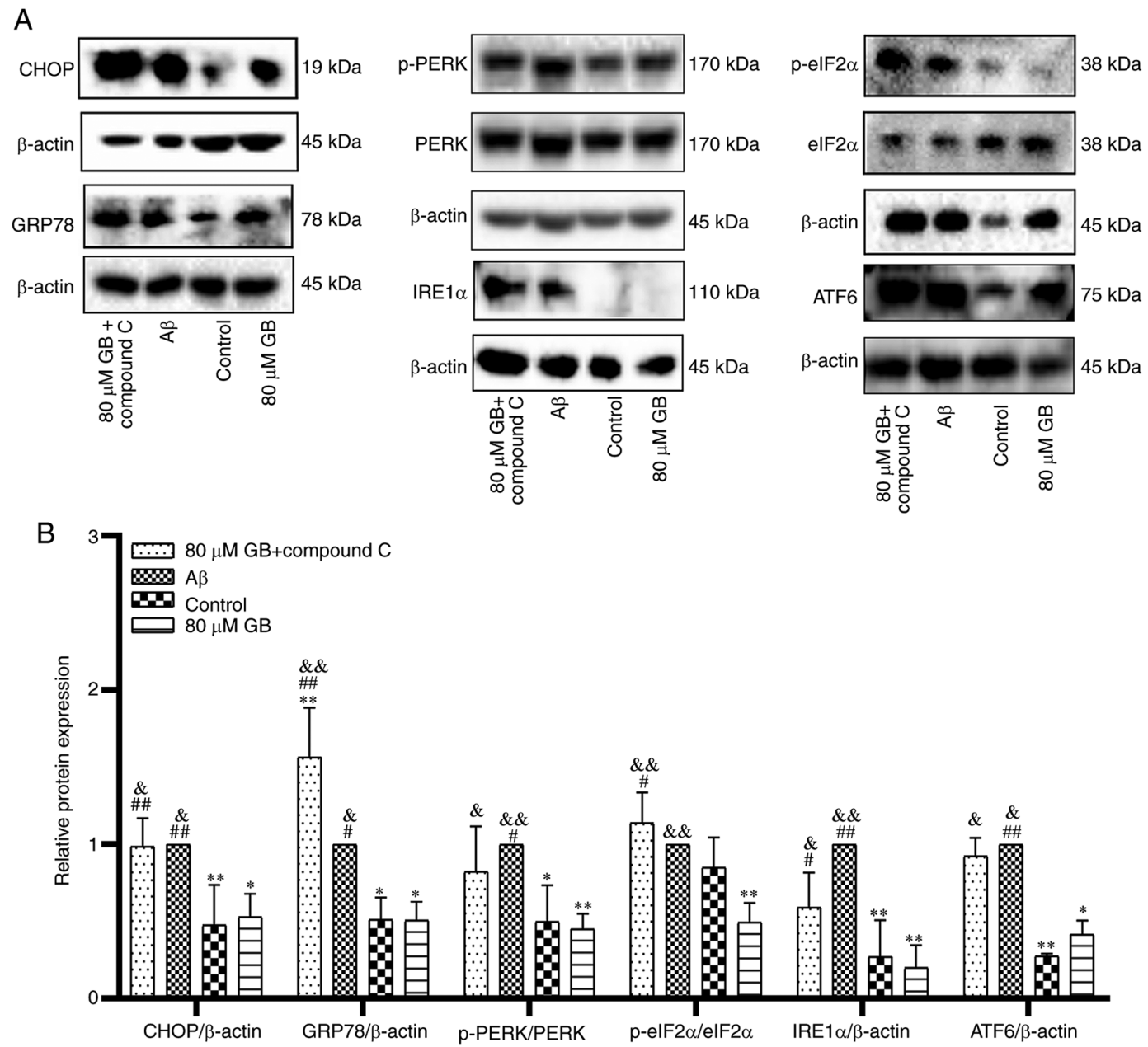

Figure 4. Compound C prevents GB-inhibits protein expressions of ERS in astrocytes. (A) Western blotting image and (B) western blotting data of protein expression levels of ERS following treatment with $10 \mu \mathrm{M} \mathrm{A} \beta_{1-42}$ with $80 \mu \mathrm{M}$ GB or treated with $10 \mu \mathrm{M} A \beta 1-42$ or $10 \mu \mathrm{M} \mathrm{A} \beta_{1-42}+80 \mu \mathrm{M}$ GB $+10 \mu \mathrm{M}$ compound $\mathrm{C}$ for $24 \mathrm{~h} .{ }^{*} \mathrm{P}<0.05$ and ${ }^{\# \#} \mathrm{P}<0.01$ vs. control group, ${ }^{*} \mathrm{P}<0.05$ and ${ }^{* *} \mathrm{P}<0.01$ vs. A $\beta$ group, ${ }^{\circledR} \mathrm{P}<0.05$ and ${ }^{\& \&} \mathrm{P}<0.01$ vs. $80 \mu \mathrm{M}$ GB group. GB, ginkgolide $\mathrm{B}$; ERS, endoplasmic reticulum stress; $A \beta, \beta$-amyloid; p-, phosphorylated; GRP78, binding immunoglobulin protein; PERK, protein kinase R like endoplasmic reticulum kinase; eIF2 $\alpha$, eukaryotic translation initiation factor 2 subunit 1; eIF2 $\alpha$, inositol-requiring enzyme $1 \alpha$; ATF6, activating transcription factor 6.
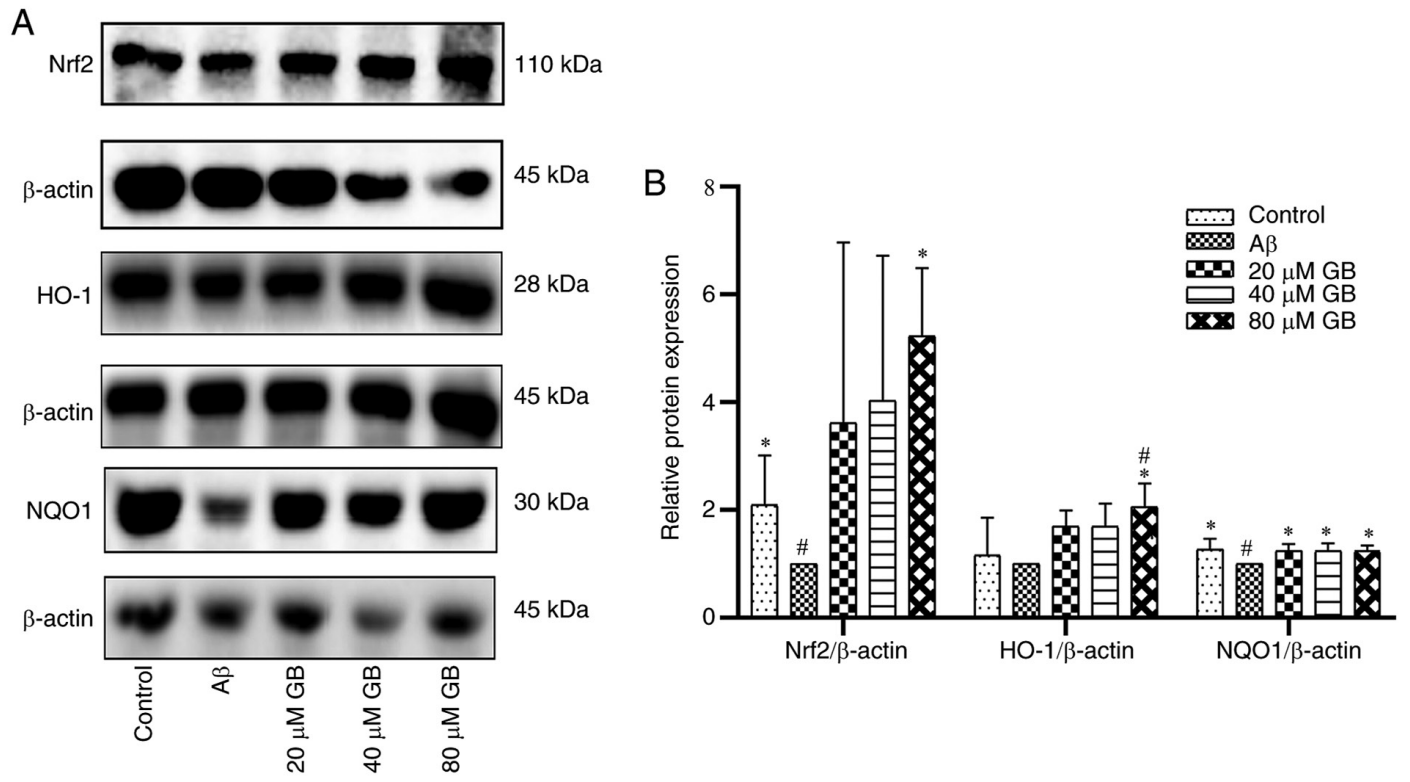

Figure 5. Effect of GB on protein expressions in Nrf2-HO-1-NQO1 induced by A $\beta_{1-42}$ in astrocytes. (A) Western blotting image and (B) western blotting data of protein expression levels of Nrf2, HO-1 and NQO1 following treatment with $10 \mu \mathrm{M} \mathrm{A} \beta_{1-42}$ with different GB concentration $(20,40$ and $80 \mu \mathrm{M} \mathrm{GB})$ or treated with $10 \mu \mathrm{M} \mathrm{A} \beta_{1-42}$ for $24 \mathrm{~h}$. ${ }^{\prime \prime} \mathrm{P}<0.05$ vs. control group, ${ }^{*} \mathrm{P}<0.05$ vs. A $\beta$ group. GB, ginkgolide $\mathrm{B} ; \mathrm{A} \beta, \beta$-amyloid; Nrf2, nuclear factor erythroid 2-related factor 2; HO-1, heme oxygenase 1; NQO1, NAD(P)H dehydrogenase (quinone 1). 


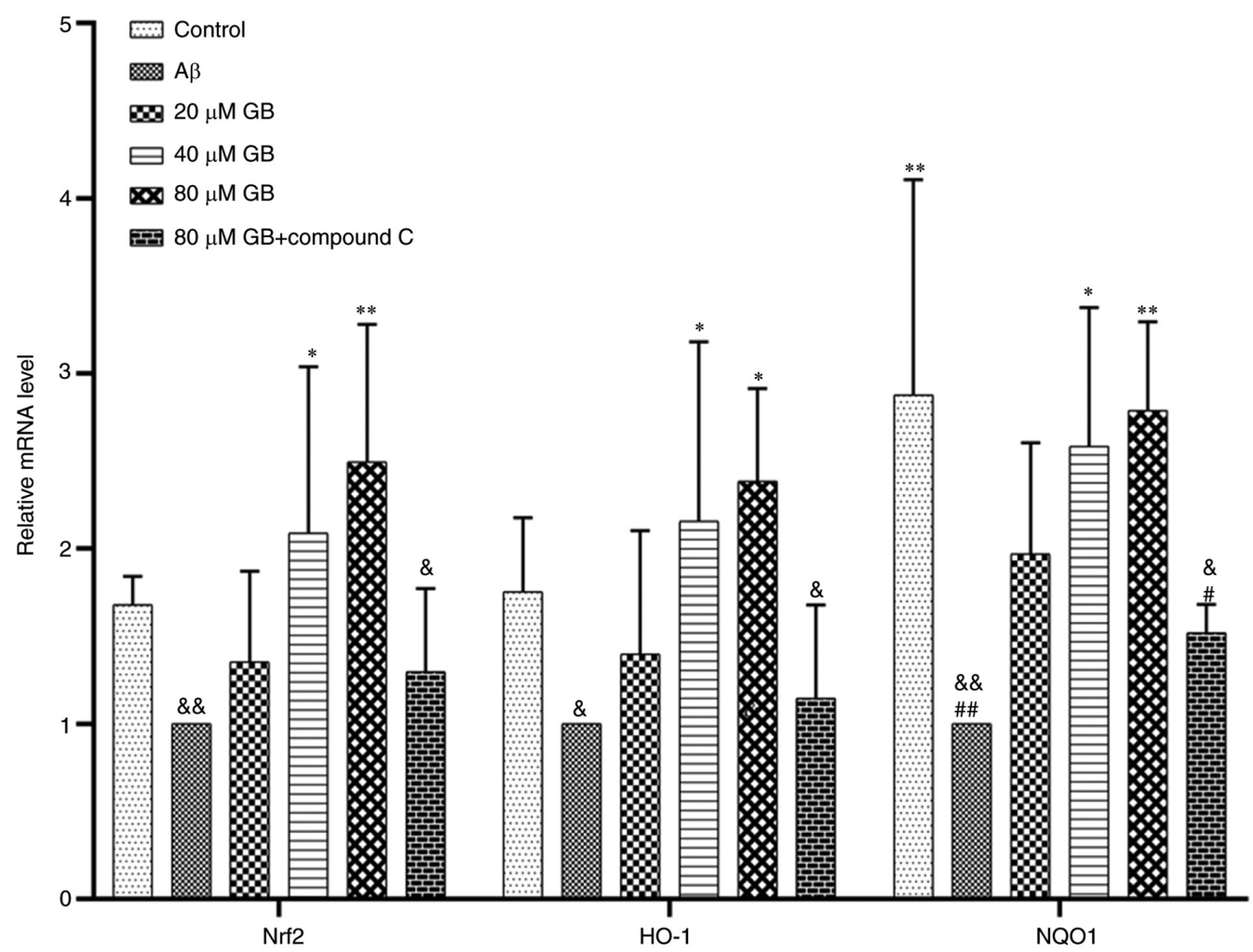

Figure 6. Effect of GB on gene expressions of Nrf2-HO-1-NQO1 induced by A $\beta 1-42$ in astrocytes. Reverse transcription-quantitative PCR data of relative mRNA expression levels of Nrf2, HO-1 and NQO1 following treatment with $10 \mu \mathrm{M} \mathrm{A} \beta_{1-42}$ with different GB concentration $(20,40,80 \mu \mathrm{M}$ GB) or treated with $10 \mu \mathrm{M} \mathrm{A} \beta 1-42$ or treated with $10 \mu \mathrm{M} \mathrm{A} \beta 1-42+80 \mu \mathrm{M} \mathrm{GB}+10 \mu \mathrm{M}$ compound $\mathrm{C}$ for $24 \mathrm{~h} .{ }^{*} \mathrm{P}<0.05$ and ${ }^{\# \#} \mathrm{P}<0.01$ vs. control group, ${ }^{*} \mathrm{P}<0.05$ and ${ }^{* *} \mathrm{P}<0.01$ vs. $\mathrm{A} \beta$ group, ${ }^{\circledR} \mathrm{P}<0.05$ and ${ }^{\&}{ }^{\&} \mathrm{P}<0.01$ vs. $80 \mu \mathrm{M}$ GB group. GB, ginkgolide B; Nrf2, nuclear factor erythroid 2-related factor 2; HO-1, heme oxygenase 1; NQO1, $\mathrm{NAD}(\mathrm{P}) \mathrm{H}$ dehydrogenase (quinone 1); $\mathrm{A} \beta, \beta$-amyloid.

A
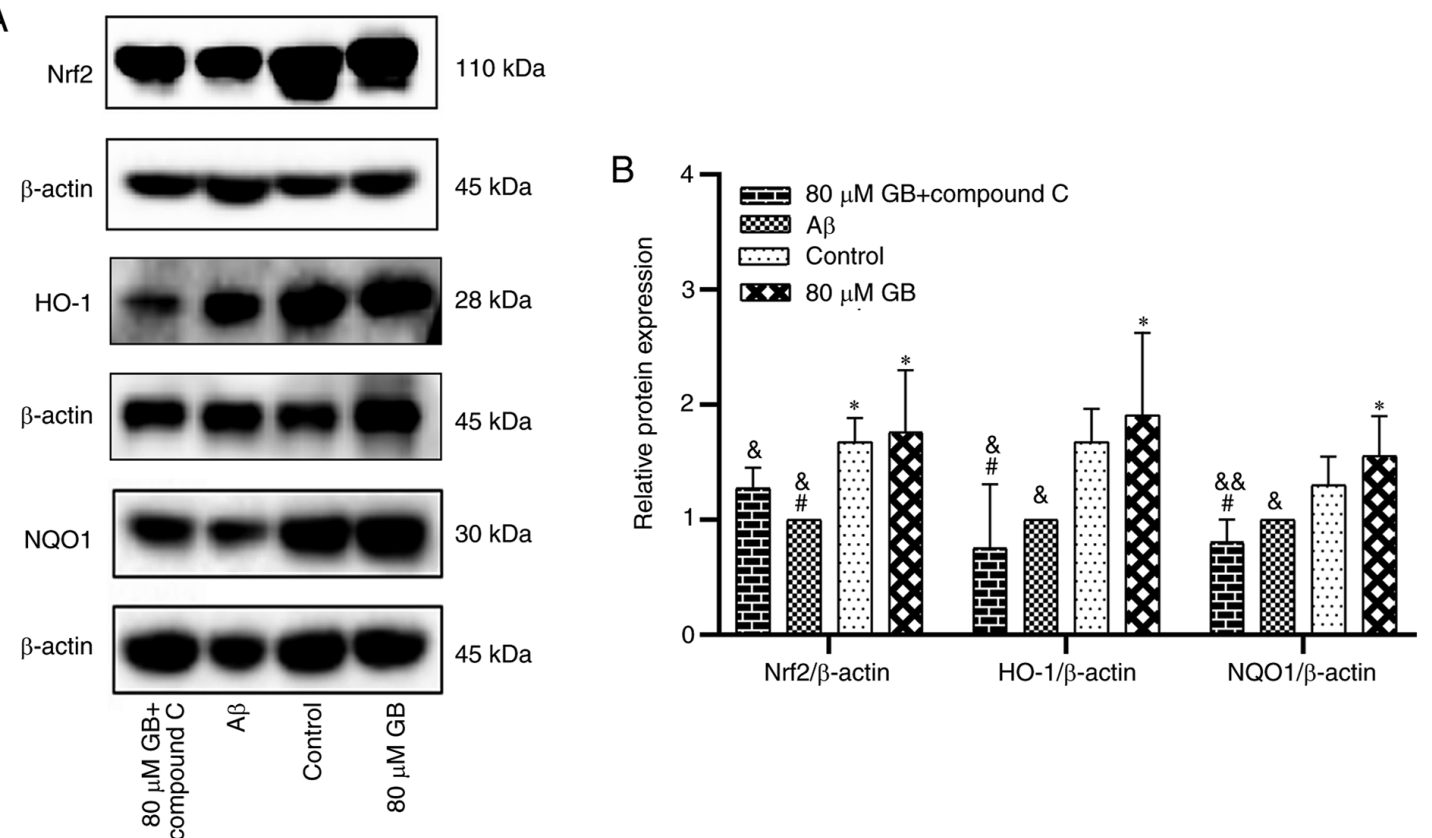

Figure 7. Compound C inhibits GB-activated protein expressions of Nrf2-HO-1-NQO1 in astrocytes. (A) Western blotting image and (B) western blotting data of protein expression levels of Nrf2, HO-1 and NQO1 following treatment with $10 \mu \mathrm{M} \mathrm{A} \beta_{1-42}$ with $80 \mu \mathrm{M}$ GB or treated with $10 \mu \mathrm{M} \mathrm{A} \beta_{1-42}$ or $10 \mu \mathrm{M} \mathrm{A} \beta_{1-42}+$ $80 \mu \mathrm{M} \mathrm{GB}+10 \mu \mathrm{M}$ compound $\mathrm{C}$ for $24 \mathrm{~h} .{ }^{~} \mathrm{P}<0.05$ vs. control group, ${ }^{*} \mathrm{P}<0.05$ vs. $\mathrm{A} \beta$ group, ${ }^{\circledR} \mathrm{P}<0.05$ and ${ }^{\text {\& }} \mathrm{P}<0.01$ vs. $80 \mu \mathrm{M}$ GB group. GB, ginkgolide $\mathrm{B}$; $\mathrm{Nrf2}$, nuclear factor erythroid 2-related factor 2; HO-1, heme oxygenase 1; NQO1, NAD(P)H dehydrogenase (quinone 1); $\mathrm{A} \beta, \beta$-amyloid.

were performed to confirm that $A \beta_{1-42}$ increased the expression of astrocyte ERS markers, leading to increased expression of apoptotic protein CHOP. However, GB could protect astrocytes from apoptosis by halting $A \beta_{1-42}$-induced ERS. This 

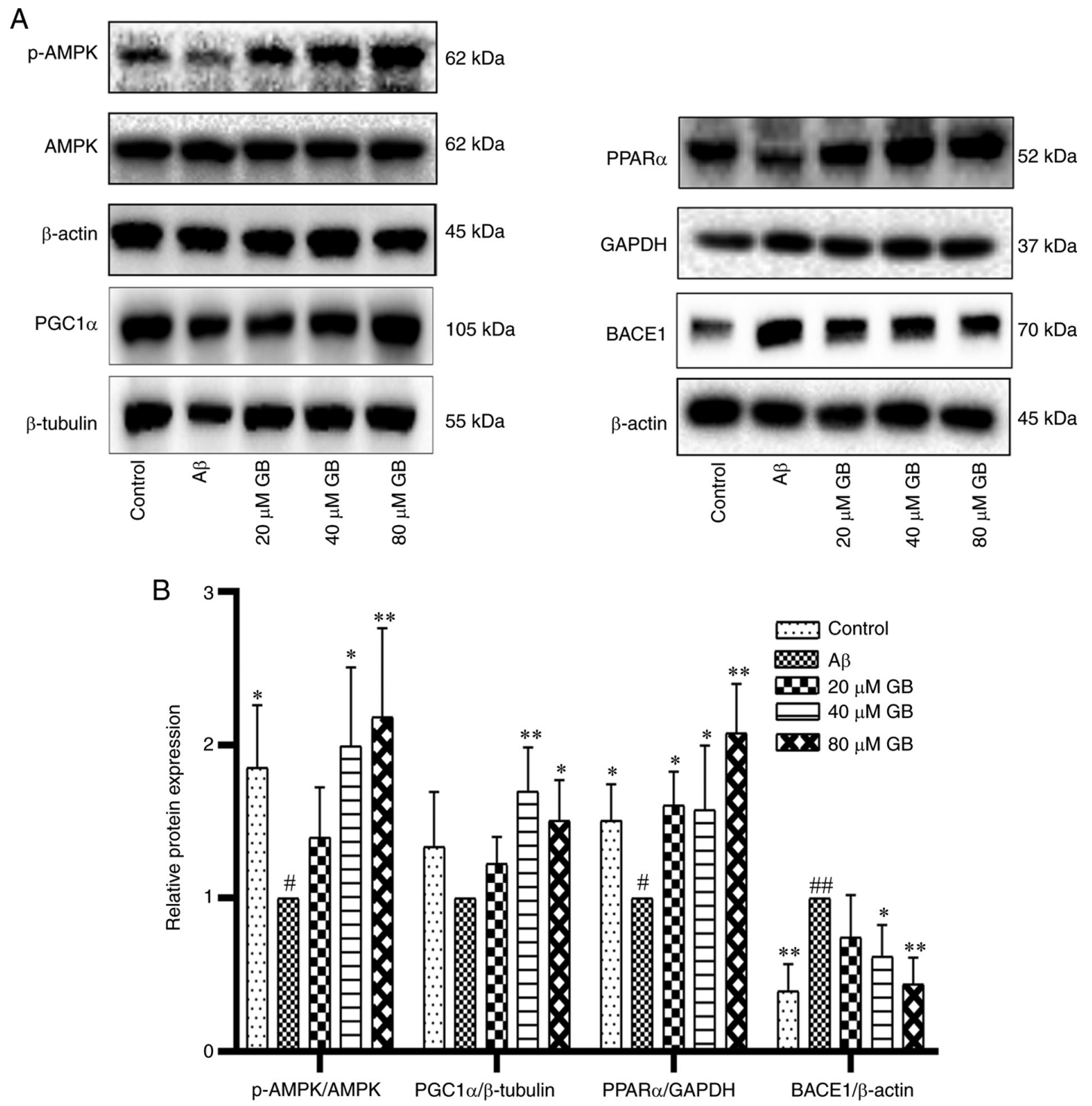

Figure 8. Effect of GB on the expression of related proteins by AMPK pathway induced by A $\beta_{1-42}$ in astrocytes. (A) Western blotting image and (B) western blotting data of protein expression levels of p-AMPK, PGC1 $\alpha$, PPAR $\alpha$ and BACE1 following treatment with $10 \mu \mathrm{M}$ A $\beta_{1-42}$ with different GB concentration (20, 40 and $80 \mu \mathrm{M} \mathrm{GB}$ ) or treated with $10 \mu \mathrm{M} \mathrm{A} \beta_{1-42}$ for $24 \mathrm{~h} .{ }^{~} \mathrm{P}<0.05$ and ${ }^{\# \#} \mathrm{P}<0.01$ vs. control group, ${ }^{*} \mathrm{P}<0.05$ and ${ }^{* *} \mathrm{P}<0.01$ vs. A $\beta$ group. GB, ginkgolide $\mathrm{B}$; AMPK, 5' adenosine monophosphate-activated protein kinase; A $\beta$, $\beta$-amyloid; p-, phosphorylated; PGC1 $\alpha$, proliferator-activated receptor $\gamma$ coactivator $1 \alpha$; PPAR $\alpha$, peroxisome proliferator-activated receptor $\alpha$; BACE1, amylase $\beta$ secretase 1.

finding showed that $A \beta_{1-42}$ protected astrocytes by decreasing the expression of ERS-related proteins in AD.

Evidence demonstrates that OS is an incipient factor that leads to cognitive dysfunction (42). In addition, the levels of OS products is clearly increased in the brain tissues of patients with $\mathrm{AD}(43,44)$ so that the brains are in a state of high oxidative stress and oxidative injury occurs earlier than senile plaques and neurofibrillary tangles $(45,46)$. In addition, mitochondrial OS, abnormal mitochondrial functions, their interaction $(47,48)$ and ROS take part in the pathological progression of AD (49). In vivo and in vitro studies confirm that $\mathrm{A} \beta$ stimulates $\mathrm{OS}$ in the brain tissues via varied pathways $(50,51)$. The products of OS also induced $A \beta$ deposition to cause abnormal energy metabolism, mitochondrial dysfunction, even resulting in apoptosis which induces memory loss and cognitive dysfunction (52). Astrocytes participate in the physiological processes of all nervous system diseases and are critical in protecting neurons (53). The experimental results from the present study demonstrated that GB improved the activity of $A \beta_{1-42}$-induced antioxidant enzymes SOD and GSH-Px and decreased the content of MDA and ROS, thus inhibiting the increase in the level of $A \beta_{1-42}$-induced mitochondrial superoxides to decrease the generation of ROS. The present study also explored the involvement of the Nrf2 pathway in the mechanism of GB for improving $A \beta_{1-42}$-induced OS. Nrf2 has been verified as a protective factor in the pathological changes in AD (54). Hence, cognitive dysfunction in Nrf2-deficient mice was more serious and $A \beta$ deposition and astrocyte activation clearly increased. In addition, the expression of the Nrf2 pathway in the brain tissues of animals with AD distinctly decreased. Activating the Nrf2 signaling pathway ameliorates OS, actively protects nerves and improves the spatial learning ability of mice with AD $(39,40)$. The Nrf2-HO-1-NQO1 pathway is critical in preventing OS and also serves as an antioxidant transcription factor. When an organism is stimulated by external factors, Nrf2 dissociates from Kelch-like ECH-associated protein 1 


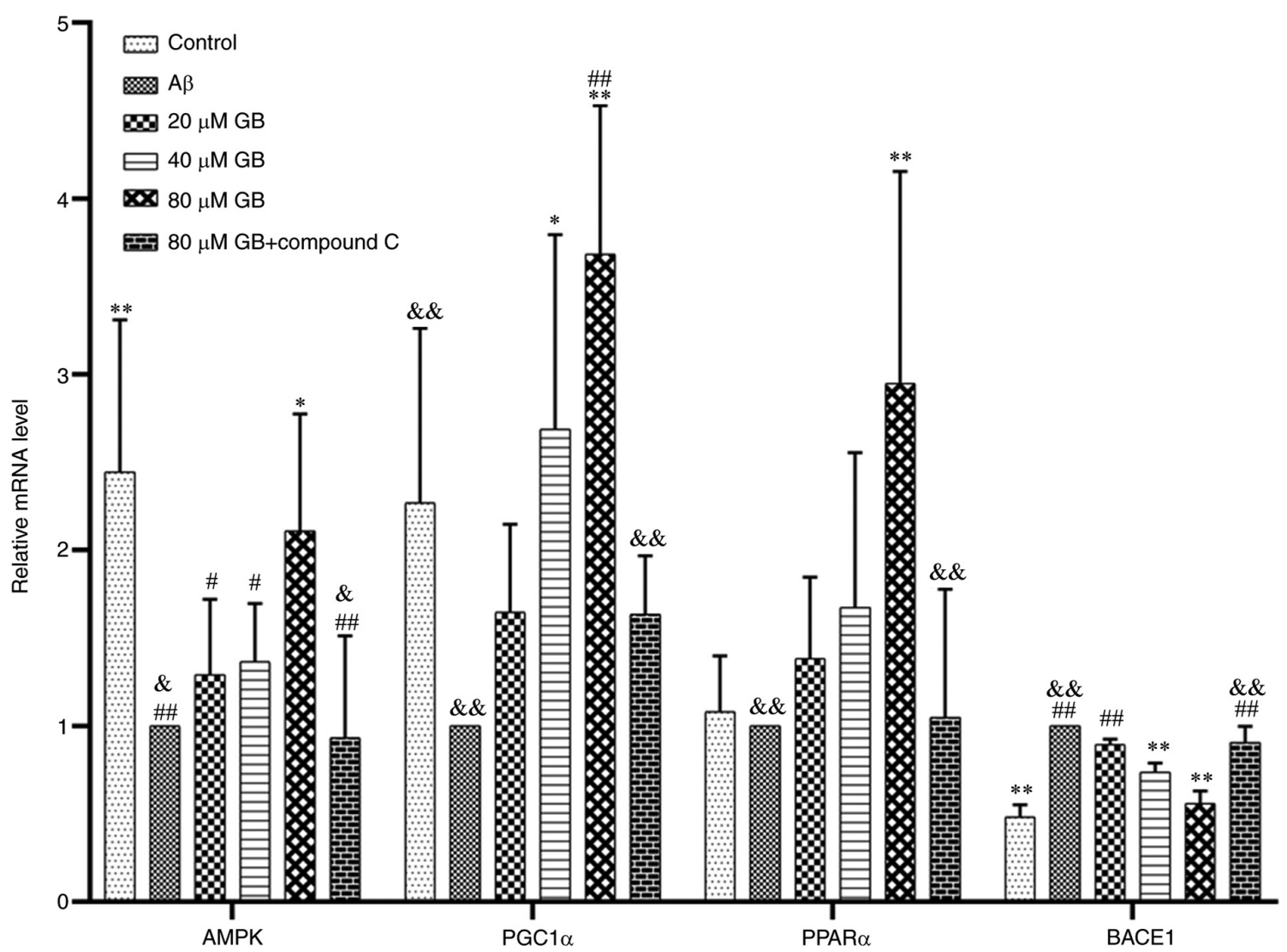

Figure 9. Effect of GB on gene expressions of AMPK pathway induced by $A \beta_{1-42}$ in astrocytes. Reverse transcription-quantitative PCR data of relative mRNA expression levels of AMPK, PGC1 $\alpha$, PPAR $\alpha$ and BACE1 were treated with $10 \mu \mathrm{M} \mathrm{A} \beta_{1-42}$ with different GB concentration $(20,40,80 \mu \mathrm{M}$ GB) or treated with $10 \mu \mathrm{M} \mathrm{A} \beta_{1-42}$ or treated with $10 \mu \mathrm{M} \mathrm{A} \beta_{1-42}+80 \mu \mathrm{M} \mathrm{GB}+10 \mu \mathrm{M}$ compound $\mathrm{C}$ for $24 \mathrm{~h} .{ }^{~}{ }^{*} \mathrm{P}<0.05$ and ${ }^{\# \#} \mathrm{P}<0.01$ vs. control group, ${ }^{*} \mathrm{P}<0.05$ and ${ }^{* * *} \mathrm{P}<0.01$ vs. $\mathrm{A} \beta$ group, ${ }^{\circledR} \mathrm{P}<0.05$ and ${ }^{\&} \& \mathrm{P}<0.01$ vs. $80 \mu \mathrm{M}$ GB group. GB, ginkgolide B; AMPK, 5 ' adenosine monophosphate-activated protein kinase; $\mathrm{A} \beta, \beta$-amyloid; PGCl $\alpha$, proliferator-activated receptor $\gamma$ coactivator $1 \alpha$; PPAR $\alpha$, peroxisome proliferator-activated receptor $\alpha$; BACE1, amylase $\beta$ secretase 1 .

in the cytoplasm and moves to the nucleus after activation to recognize antioxidant response elements and initiate the transcription of downstream antioxidant genes, including HO-1 and NQO1 (55). The results of the present study showed that GB increases the gene and protein expression levels of Nrf2-HO-1-NQO1 in astrocytes, thus exerting antioxidant activity to prevent OS and apoptosis and protect astrocytes from $A \beta_{1-42}$-induced injury.

Energy metabolism disorder is a key pathological event in the early progression of AD because ATP can inhibit polymer of $A \beta$, weaken its neutral toxicity and decrease the formation of senile plaques, thus antagonizing $\mathrm{AD}(56,57)$. Insufficient levels of ATP accelerate the pathogenesis of AD $(58,59)$. $\beta$-amyloid precursor protein (APP) and A $\beta$ accumulate on the mitochondrial membranes and cause functional and structural injury to mitochondria and a metabolic decline in mitochondrial energy, thus decreasing the generation of ATP (60) and disrupting the normal functions of neural cells. The experimental results from the present study identified that GB improved the levels of $A \beta_{1-42}$-induced ATP, thereby improving mitochondrial damage and hence stabilizing energy metabolism. However, AMPK inhibitor compound C inhibited the GB-induced improvement, which was probably associated with AMPK. AMPK is vital in metabolic homeostasis (61). A previous study found that the levels of $A \beta$ increase when the levels of hippocampal p-AMPK decrease in 6-month-old
APP/PS1 mice. That is, decreasing AMPK activity exacerbates the pathology of AD (62). BACE1 mediates the first cleavage of APP and is the key and speed-limiting enzyme in the process of $A \beta$ generation (63). AMPK inhibits the expression and activity of BACE1 and then regulates APP cleavage to reduce $\mathrm{A} \beta$ production (64). AMPK activates PGC-1 $\alpha$ (59), which is the transcriptional co-activator regulating the expression of energy metabolism-related genes. PGC-1 $\alpha$ improves the synthesis and metabolism in mitochondria, increases the number of mitochondria and increases the content of ATP (65). PGC-1 family members possess multifunctional transcriptional co-activation effects. They combine with PPARs and act as a "molecular switch' in a number of energy metabolic signaling pathways, which regulate glycolipid metabolism and energy metabolism $(66,67)$. A previous study demonstrates that the expression of PGC1 $\alpha$ in the brain tissues of patients with AD declines, leading to abnormal functioning of mitochondria (68). PGC1 $\alpha$ inhibits the generation of $\mathrm{A} \beta$ and a decrease in the expression of PGC1 $\alpha$ may be involved in the pathological progression of AD (69). PPAR $\alpha$ does not influence the generation of $A \beta$, but its excessive expression decreases the expression level of $A \beta$ (70,71). In the present study, $A \beta_{1-42}$ inhibited the expression of the AMPK-PGC1 $\alpha$-PPAR $\alpha$ pathway and increased the expression of BACE1 in astrocytes, which was in accordance with the aforementioned findings. That is, $A \beta_{1-42}$ induced the dysfunction of mitochondrial energy metabolism and also 

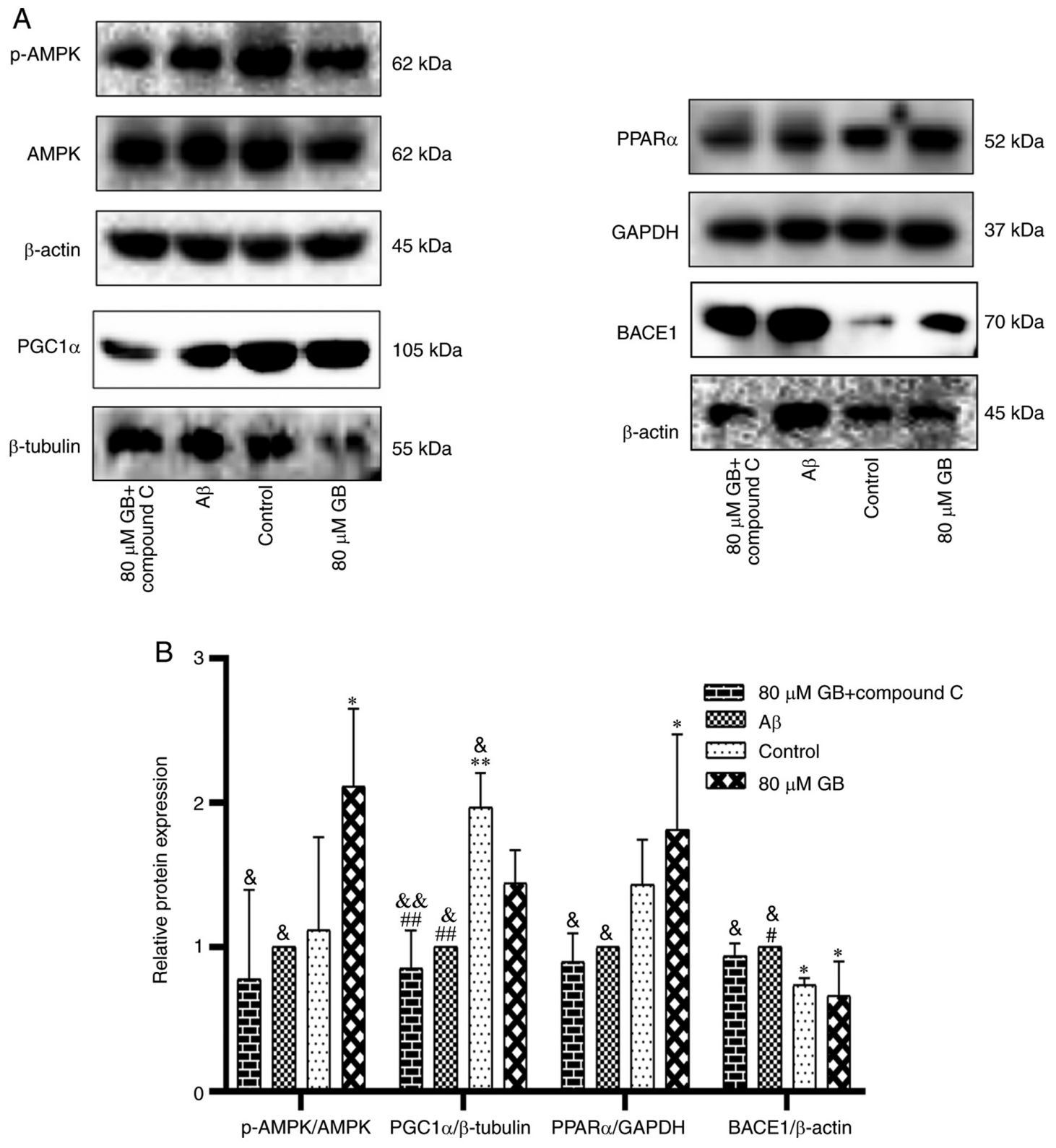

Figure 10. Compound C inhibits GB-activated protein expressions of AMPK pathway in astrocytes. (A) Western blotting image and (B) western blotting data of protein expression levels of p-AMPK, PGCl $\alpha$, PPAR $\alpha$ and BACE1 following treatment with $10 \mu \mathrm{M}$ A $\beta_{1-42}$ with $80 \mu \mathrm{M}$ GB or treated with $10 \mu \mathrm{M}$ A $\beta_{1-42}$ or $\mathrm{A} \beta_{1-42}+80 \mu \mathrm{M} \mathrm{GB}+10 \mu \mathrm{M}$ compound $\mathrm{C}$ for $24 \mathrm{~h} .{ }^{\#} \mathrm{P}<0.05$ and ${ }^{\# \#} \mathrm{P}<0.01$ vs. control group, ${ }^{*} \mathrm{P}<0.05$ and ${ }^{* *} \mathrm{P}<0.01$ vs. A $\beta$ group, ${ }^{\text {\& }} \mathrm{P}<0.05$ and ${ }^{\text {\&\&}} \mathrm{P}<0.01 \mathrm{vs} .80 \mu \mathrm{M}$ GB group. GB, ginkgolide B; AMPK, 5' adenosine monophosphate-activated protein kinase; p-, phosphorylated; PGCl $\alpha$, proliferator-activated receptor $\gamma$ coactivator $1 \alpha$; PPAR $\alpha$, peroxisome proliferator-activated receptor $\alpha$; BACE1, amylase $\beta$ secretase 1 ; A $\beta$, $\beta$-amyloid.

$\mathrm{A} \beta$ generation. However, GB increased the expression of the AMPK-PGCl $\alpha$-PPAR $\alpha$ signaling pathway, indicating that GB protected astrocytes via suppressing the inhibition of energy metabolism of $\mathrm{A} \beta_{1-42}$ to reduce the generation of $\mathrm{A} \beta$. However, AMPK inhibitor compound $\mathrm{C}$ inhibited the functions of $\mathrm{GB}$, implying that GB regulated energy metabolism and A $\beta$ generation via likely activating the AMPK-PGC1 $\alpha$-PPAR $\alpha$ pathway.

Energy metabolism causes environmental disorders of the endoplasmic reticulum to result in ERS (72). However, the persistence of metabolic injury causes neural damage resulting from prolonged activation of ERS $(73,74)$. AMPK is the key sensor of the state of energy in eukaryotic cells and has strong effects on ERS, insulin resistance and lipid metabolism $(75,76)$. Activating AMPK can help prevent hypoxic injury, atherosclerosis and heart injury caused by ERS $(77,78)$. In the present study, $A \beta_{1-42}$ increased the expression of astrocyte ERS markers and resulted in higher expression levels of the apoptotic protein CHOP. GB inhibited ERS and apoptosis, while AMPK inhibitor compound $\mathrm{C}$ inhibited GB-induced ERS and apoptosis. These findings indicated that GB impeded the activation of ERS caused by energy metabolism disorders and suppressed ERS-related signaling pathways through the AMPK signaling pathway to inhibit $\mathrm{A} \beta_{1-42}$-induced astrocyte injury and protect astrocytes. ERS can increase the generation of ROS. Conversely, the generation of ROS can induce ERS. Hence, a strong correlation exists between ROS and ERS $(79,80)$. A previous study noted that activated AMRK is associated with the regulation of the Nrf2 signaling pathway (81). The present study demonstrated that 
the antioxidant activity of GB prevented OS and apoptosis via increasing the expression of Nrf2-HO-1-NQO1 in astrocytes to protect astrocytes from $A \beta_{1-42}$-induced injury. AMPK inhibitor compound $\mathrm{C}$ inhibited the improvement in GB-induced OS and apoptosis. Hence, the GB probably acted by promoting the activation of AMPK and Nrf2 to increase the gene and protein expression levels of HO-1 and NQO1. In other words, GB ameliorated $\mathrm{A} \beta_{1-42}$-induced OS responses, which was probably related to the activation of AMPK-Nrf2-HO-1-NQO1 signaling pathways.

In conclusion, $\mathrm{GB}$ protects against $\mathrm{A} \beta_{1-42}$-induced cell apoptosis by inhibiting ERS, OS and energy metabolism disorders via activating AMPK signaling pathways. These findings might provide an innovative insight into the treatment of $\mathrm{A} \beta$-related AD using GB.

\section{Acknowledgements}

Not applicable.

\section{Funding}

The present study was sponsored by the National Natural Science Foundation of China (grant no. U1603285). The funders had no role in study design and collection, analysis and interpretation of data, or the decision to submit the work for publication.

\section{Availability of data and materials}

The data used and/or analyzed during the current study are available from the corresponding author on reasonable request.

\section{Authors' contributions}

JW and LZ confirm the authenticity of all the raw data. JW designed the experiments, performed the experimental procedures, analyzed the data, and wrote the manuscript. YD and LZ performed experimental procedures, and analyzed the data. ZW designed experiments and reviewed the manuscript. WX and JZ conceived the project, designed experiments, and reviewed the manuscript. All authors read and approved the final manuscript.

\section{Ethics approval and consent to participate}

All procedures related to the use and care of animals in the present study were approved by the Ethics Committee for the Use of Experimental Animals of Jiangsu Kanion Pharmaceutical Co. Ltd. State Key Laboratory of New Pharmaceutical Process for Traditional Chinese Medicine (approval no. 2019012).

\section{Patient consent for publication}

Not applicable.

\section{Competing interests}

The authors declare that they have no competing interests.

\section{References}

1. Maclennan KM, Darlington CL and Smith PF: The CNS effects of Ginkgo biloba extracts and ginkgolide B. Prog Neurobiol 67: 235-257, 2002.

2. Yang P, Cai X, Zhou K, Lu C and Chen W: A novel oil-body nanoemulsion formulation of Ginkgolide B: Pharmacokinetics study and in vivo pharmacodynamics evaluations. J Pharm Sci 103: 1075-1084, 2014

3. Bate C, Tayebi M and Williams A: Ginkgolides protect against amyloid- $\beta 1-42$-mediated synapse damage in vitro. Mol Neurodegener 3: 1, 2008.

4. Werneke U, Turner T and Priebe S: Complementary medicines in psychiatry: Review of effectiveness and safety. Br J Psychiatry 188: 109-121, 2006.

5. Jean NS, Kathy GW, Pauline M and Stacy H: Dysgraphia in Alzheimer's disease: A review for clinical and research purposes. J Speech Lang Hear Res 49: 1313-1330, 2006.

6. Nobuyuki K: Diabetes mellitus induces Alzheimer's disease pathology: Histopathological evidence from animal models. Int J Mol Sci 17: 503, 2016.

7. Ballard C, Gauthier S, Corbett A, Brayne C and Jones E: Alzheimer's disease. Lancet 377: 1019-1031, 2011.

8. Shankar GM, Li S, Mehta TH, Garcia-Munoz A, Shepardson NE, Smith I, Brett FM, Farrell MA, Rowan MJ, Lemere CA, et al: Amyloid- $\beta$ protein dimers isolated directly from Alzheimer's brains impair synaptic plasticity and memory. Nat Med 14: 837-842, 2008

9. Wyss-Coray T, Loike JD, Brionne TC, Lu E and Husemann J: Adult mouse astrocytes degrade amyloid-beta in vitro and in situ. Nat Med 9: 453-457, 2003.

10. Nielsen HM, Veerhuis R, Bo H and Janciauskiene S: Binding and uptake of Abeta $_{1-42}$ by primary human astrocytes in vitro. Glia 57: 978-988, 2009.

11. Basak JM, Verghese PB, Yoon H, Kim J and Holtzman DM: Low-density lipoprotein receptor represents an apolipoprotein E-independent pathway of $\mathrm{A} \beta$ uptake and degradation by astrocytes. J Biol Chem 287: 13959-13971, 2012.

12. Thal DR, Schultz C, Dehghani F, Yamaguchi H, Braak H and Braak E: Amyloid beta-protein (Abeta)-containing astrocytes are located preferentially near N-terminal-truncated Abeta deposits in the human entorhinal cortex. Acta Neuropathol 100: 608-617, 2000.

13. Yang ZZ, Li J, Li SX, Feng W and Wang H: Effect of ginkgolide $\mathrm{B}$ on striatal extracellular amino acids in middle cerebral artery occluded rats. J Ethnopharmacol 136: 117-122, 2011.

14. Poon WW, Carlos AJ, Aguilar BL, Berchtold NC, Kawano CK, Zograbyan V, Yaopruke T, Shelanski M and Cotman CW: $\beta$-Amyloid $(A \beta)$ oligomers impair brain-derived neurotrophic factor retrograde trafficking by down-regulating ubiquitin C-terminal hydrolase, UCH-L1. J Biol Chem 288: 16937-16948, 2013.

15. Ihara Y, Morishima-Kawashima M and Nixon R: The ubiquitin-proteasome system and the autophagic-lysosomal system in Alzheimer disease. Cold Spring Harb Perspect Med 2: a006361, 2012.

16. Iurlaro $\mathrm{R}$ and Muñoz-Pinedo $\mathrm{C}$ : Cell death induced by endoplasmic reticulum stress. FEBS J 283: 2640-2652, 2016.

17. Li HH, Lu FJ, Hung HC, Liu GY, Lai TJ and Lin CL: Humic acid increases amyloid $\beta$-induced cytotoxicity by induction of ER stress in human SK-N-MC neuronal cells. Int J Mol Sci 16: 10426-10442, 2015.

18. Li JQ, Tai YJ, Jiang T and Tan L: Endoplasmic reticulum dysfunction in Alzheimer's disease. Mol Neurobiol 51: 383-395, 2015.

19. Umeda T, Tomiyama T, Sakama N, Tanaka S, Lambert MP, Klein WL and Mori H: Intraneuronal amyloid-beta oligomers cause cell death via endoplasmic reticulum stress, endosomal/lysosomal leakage, and mitochondrial dysfunction in vivo. J Neurosci Res 89: 1031-1042, 2011.

20. Hoozemans JJ, van Haastert ES, Nijholt DA, Rozemuller AJ, Eikelenboom P and Scheper W: The unfolded protein response is activated in pretangle neurons in Alzheimer's disease hippocampus. Am J Pathol 110: 165-172, 2005.

21. Araki E, Oyadomari S and Mori M: Endoplasmic reticulum stress and diabetes mellitus. Intern Med 42: 7-14, 2003.

22. Verri M, Pastoris O, Dossena M, Aquilani R and Bongiorno AI: Mitochondrial alterations, oxidative stress and neuroinflammation in Alzheimer's disease. Int J Immunopathol Pharmacol 25: 345-353, 2012. 
23. Su X, Wu W, Huang Z, Hu J, Lei P, Yu C, Zhao YF and Li Y: Hydrogen peroxide can be generated by tau in the presence of Cu(II). Biochem Biophys Res Commun 358: 661-665, 2007.

24. Cha M, Han S, Son S, Hong H, Cha Y, Byun J and Inhee M: Mitochondria-specific accumulation of amyloid $\beta$ induces mitochondrial dysfunction leading to apoptotic cell death. PLoS One 7: e34929, 2012.

25. Borghi R, Patriarca S, Traverso N, Piccini A, Storace D, Garuti A, Cirmena G, Odetti P and Tabaton M: The increased activity of BACE1 correlates with oxidative stress in Alzheimer's disease. Neurobiol Aging 28: 1009-1014, 2007.

26. Ribeiro MF, Genebra T, Rego AC, Rodrigues CMP and Solá S: Amyloid $\beta$ peptide compromises neural stem cell fate by irreversibly disturbing mitochondrial oxidative state and blocking mitochondrial biogenesis and dynamics. Mol Neurobiol 56 3922-3936, 2019.

27. Jahanshahi M, Sadeghi Y, Hosseini A, Naghdi N and Marjani A: The effect of spatial learning on the number of astrocytes in the CA3 subfield of the rat hippocampus. Singapore Med J 49: 388-391, 2008

28. Kawano H, Oyabu K, Yamamoto H, Eto K, Adaniya Y, Kubota K Watanabe T, Hiranoiwata A, Nabekura J, Katsurabayashi S and Iwasaki K: Astrocytes with previous chronic exposure to amyloid $\beta$-peptide fragment 1-40 suppress excitatory synaptic transmission. J Neurochem 143: 624-634, 2017.

29. Zhang N, Xiong WW, Yuan X and Zhang W: Culture method of rat fetal hippocampal neurons and astrocytes. Acta Neuropharmacol 7: 24-28, 2017.

30. Aguirre-Rueda D, Guerra-Ojeda S, Aldasoro M, Iradi A, Obrador E, Ortega A, Mauricio MD, Vila JM and Valles SL: Astrocytes protect neurons from A $\beta 1-42$ peptide-induced neurotoxicity increasing TFAM and PGC- 1 and decreasing PPAR- $\gamma$ and SIRT-1. International Journal of Medical ences 12: 48-56, 2015.

31. Livak KJ and Schmittgen TD: Analysis of relative gene expression data using real-time quantitative PCR and the 2(-Delta Delta C(T)) method. Methods 25: 402-408, 2002.

32. Hardy J and Higgins G: Alzheimer's disease: The amyloid cascade hypothesis. Science 256: 184-185, 1992.

33. Jan A, Gokce O, Luthi-Carter R and Lashuel HA: The ratio of monomeric to aggregated forms of Abeta40 and Abeta42 is an important determinant of amyloid-beta aggregation, fibrillogenesis, and toxicity. J Biol Chem 283: 28176-28189, 2008.

34. Mulder SD, Veerhuis R, Blankenstein MA and Nielsen HM: The effect of amyloid associated proteins on the expression of genes involved in amyloid- $\beta$ clearance by adult human astrocytes. Exp Neurol 233: 373-379, 2012.

35. Paris D, Beaulieu-Abdelahad D, Bachmeier C, Reed J, Ait-Ghezala G, Bishop A, Chao J, Mathura V, Crawford F and Mullan M: Anatabine lowers Alzheimer's A $\beta$ production in vitro and in vivo. Eur J Pharmacol 670: 384-391, 2011

36. Mohamed A and Chaves EPd: A $\beta$ internalization by neurons and glia. Int J Alzheimers Dis 2011: 127984, 2011.

37. Fan J, Donkin J and Wellington C: Greasing the wheels of Abeta clearance in Alzheimer's disease: The role of lipids and apolipoprotein E. Biofactors 35: 239-248, 2009.

38. Phillips EC, Croft CL, Kurbatskaya K, O'Neill MJ, Hutton ML, Hanger DP, Garwood CJ and Noble W: Astrocytes and neuroinflammation in Alzheimer's disease. Biochem Soc Trans 42: $1321-1325,2014$

39. Unterberger U, Höftberger R, Gelpi E, Flicker H, Budka H and Voigtländer T: Endoplasmic reticulum stress features are prominent in Alzheimer disease but not in prion diseases in vivo J Neuropathol Exp Neurol 65: 348-357, 2006.

40. Doyle KM, Kennedy D, Gorman AM, Gupta S, Healy S and Samali A: Unfolded proteins and endoplasmic reticulum stress in neurodegenerative disorders. J Cell Mol Med 15: 2025-2039, 2011.

41. Lindholm D, Wootz H and Korhonen L: ER stress and neurodegenerative diseases. Cell Death Differ 3: 385-392, 2006.

42. Torres L, Quaglio NB, de Souza GT, Garcia RT, Dati LM, Moreira WL, Loureiro AP, de Souza-Talarico JN, Smid J, Porto CS, et al: Peripheral oxidative stress biomarkers in mild cognitive impairment and Alzheimer's disease. J Alzheimer's Dis 26: 59-68, 2011

43. Smith CD, Carney JM, Tatsumo T, Stadtman ER, Floyd RA and Markesbery WR: Protein oxidation in aging brain. Ann N Y Acad Sci 663: 110-119, 1992.

44. Choi D, Lee Y, Hong JT and Lee H: Antioxidant properties of natural polyphenols and their therapeutic potentials for Alzheimer's disease. Brain Res Bull 87: 144-153, 2012.
45. Silva DF, Selfridge JE, Lu J, Lezi E and Swerdlow RH: Mitochondrial abnormalities in Alzheimer's Disease. Possible targets for therapeutic intervention. Adv Pharmacol 64: 83-126, 2012.

46. Darvesh AS, Carroll RT, Bishayee A, Geldenhuys WJ and Van der Schyf CJ: Oxidative stress and Alzheimer's disease: Dietary polyphenols as potential therapeutic agents. Expert Rev Neurother 10: 729-745, 2010.

47. Aliev G, Palacios HH, Walrafen B, Lipsitt AE, Obrenovich ME and Morales L: Brain mitochondria as a primary target in the development of treatment strategies for Alzheimer disease. Int J Biochem Cell Biol 41: 1989-2004, 2009.

48. Milton NG: Role of hydrogen peroxide in the aetiology of Alzheimer's disease: Implications for treatment. Drugs Aging 21: 81-100, 2004

49. Kontush A: Amyloid-beta: An antioxidant that becomes a pro-oxidant and critically contributes to Alzheimer's disease. Free Radic Biol Med 31: 1120-1131, 2001.

50. Perry G, Cash AD and Smith MA: Alzheimer disease and oxidative stress. J Biomed Biotechnol 2: 120-123, 2002.

51. Honda K, Smith MA, Zhu X, Baus D, Merrick WC, Tartakoff AM, Hattier T, Harris PL, Siedlak SL, Fujioka H, et al: Ribosomal RNA in Alzheimer disease is oxidized by bound redox-active iron. J Biol Chem 280: 20978-20986, 2005.

52. Casley CS, Canevari L, Land JM, Clark JB and Sharpe MA Beta-amyloid inhibits integrated mitochondrial respiration and key enzyme activities. J Neurochem 80: 91-100, 2002.

53. Gegg ME, Clark JB and Heales SJ: Co-culture of neurones with glutathione deficient astrocytes leads to increased neuronal susceptibility to nitric oxide and increased glutamate-cysteine ligase activity. Brain Res 1036: 1-6, 2005.

54. Tian Y, Wang W, Xu L, Li H, Wei Y, Wu Q and Jia J: Activation of Nrf2/ARE pathway alleviates the cognitive deficits in PS1V97L-Tg mouse model of Alzheimer's disease through modulation of oxidative stress. J Neurosci Res 97: 492-505, 2019.

55. Mccubrey JA, Lahair MM and Franklin RA: Reactive oxygen species-induced activation of the MAP kinase signaling pathways. Antioxid Redox Signal 8: 1775-1789, 2006.

56. Eckert A, Hauptmann S, Scherping I, Rhein V, Mullerspahn F, Gotz J and Muller WE: Soluble beta-amyloid leads to mitochondrial defects in amyloid precursor protein and tau transgenic mice. Neurodegener Dis 5: 157-159, 2008.

57. Schmidt C, Lepsverdize E, Chi SL, Das AM and Schachner M Amyloid precursor protein and amyloid beta-peptide bind to ATP synthase and regulate its activity at the surface of neural cells. Mol Psychiatry 13: 953-969, 2007.

58. Coskuner O and Murray IV: Adenosine triphosphate (ATP) reduces amyloid- $\beta$ protein misfolding in vitro. J Alzheimers Dis Jad 41: 561-574, 2014.

59. Müller WEG, Wang S, Ackermann M, Neufurth M, Steffen R, Mecja E, Muñoz-Espí R, Feng Q, Schröder HC and Wang X: Rebalancing $\beta$-amyloid-induced decrease of ATP level by amorphous nano/micro polyphosphate: Suppression of the neurotoxic effect of amyloid $\beta$-protein fragment 25-35. Int J Mol Sci 18: 2154, 2017.

60. Du H and Yan SS: Mitochondrial permeability transition pore in Alzheimer's disease: Cyclophilin D and amyloid beta. Biochim Biophys Acta 1802: 198-204,2010.

61. Ke R, Xu Q, Li C, Luo L and Huang D: Mechanisms of AMPK in the maintenance of ATP balance during energy metabolism. Cell Biol Int 42: 384-392, 2018.

62. Ou Z, Kong X, Sun X, He X, Zhang L, Gong Z, Huang J, Xu B, Long D, Li J, et al: Metformin treatment prevents amyloid plaque deposition and memory impairment in APP/PS1 mice. Brain Behav Immun 69: 351-363, 2018

63. Sun X, He G and Song W: BACE2, as a novel APP theta-secretase, is not responsible for the pathogenesis of Alzheimer's disease in Down syndrome. FASEB J 20: 1369-1376, 2006.

64. Coimbra JRM, Marques DFF, Baptista SJ, Pereira CMF, Moreira PI, Dinis TCP, Santos AE and Salvador JAR: Highlights in BACE1 inhibitors for Alzheimer's disease treatment. Front Chem 6: 178, 2018.

65. Jeon SM: Regulation and function of AMPK in physiology and diseases. Exp Mol Med 48: e245, 2016.

66. Finck BN and Kelly DP: PGC-1 coactivators: Inducible regulators of energy metabolism in health and disease. J Clin Invest 116: 615-622, 2006.

67. Tiraby $\mathrm{C}$ and Langin D: Conversion from white to brown adipocytes: A strategy for the control of fat mass? Trends Endocrinol Metab 14: 439-441, 2003 
68. Austin S and St-Pierre J: PGC1 $\alpha$ and mitochondrial metabolism-emerging concepts and relevance in ageing and neurodegenerative disorders. J Cell Sci 125: 4963-4971, 2012.

69. Ettcheto M, Petrov D, Pedros I, Alva N, Carbonell T, Beaszarate C, Pallas M, Auladell C, Folch J and Camins A: Evaluation of neuropathological effects of a high-fat diet in a presymptomatic Alzheimer's disease stage in APP/PS1 mice. J Alzheimer's Dis 54: 233-251, 2016.

70. Li Z, Li H, Zhao CH, Lv C, Zhong CJ, Xin WF and Zhang WS Protective effect of Notoginsenoside R1 on an APP/PS1 mouse model of Alzheimer's disease by up-regulating insulin degrading enzyme and inhibiting $A \beta$ accumulation. CNS Neurol Disord Drug Targets 14: 360-369, 2015.

71. Camacho IE, Serneels L, Spittaels K, Merchiers P, Dominguez D and De Strooper B: Peroxisome proliferator-activated receptor gamma induces a clearance mechanism for the amyloid-beta peptide. J Neurosci 24: 10908-10917, 2004.

72. Mamelak M: Energy and the Alzheimer brain. Neurosci Biobehav Rev 75: 297-313, 2017.

73. Biswas J, Gupta S, Verma DK and Singh S: Streptozotocin alters glucose transport, connexin expression and endoplasmic reticulum functions in neurons and astrocytes. Neuroscience 356: 151-166, 2017.

74. Park-York MJ, Kim Y and York DA: Cage food location alters energy balance and endoplasmic reticulum stress in the brain of mice. Physiol Behav 106: 158-163, 2012.

75. Grahame Hardie D: AMP-activated protein kinase: A key regulator of energy balance with many roles in human disease. J Intern Med 276: 543-559, 2014.
76. Boß M,Newbatt Y,Gupta S, Collins I,Brüne B and Namgaladze D: AMPK-independent inhibition of human macrophage ER stress response by AICAR. Sci Rep 6: 32111, 2016.

77. Yeh $\mathrm{CH}$, Chen TP, Wang YC, Lin YM and Fang SW: AMP-activated protein kinase activation during cardioplegia-induced hypoxia/reoxygenation injury attenuates cardiomyocytic apoptosis via reduction of endoplasmic reticulum stress. Mediators Inflamm 2010: 130636, 2010.

78. Gao F, Chen J and Zhu H: A potential strategy for treating atherosclerosis: Improving endothelial function via AMP-activated protein kinase. Sci China Life Sci 61: 1024-1029, 2018.

79. Cao SS and Kaufman RJ: Endoplasmic reticulum stress and oxidative stress in cell fate decision and human disease. Antioxid Redox Signal 21: 396-413, 2014.

80. Zheng W, Wang B, Si M, Zou H, Song R, Gu J, Yuan Y, Liu X, Zhu G, Bai J, et al: Zearalenone altered the cytoskeletal structure via ER stress-autophagy-oxidative stress pathway in mouse TM4 Sertoli cells. Sci Rep 8: 3320, 2018.

81. Wu P, Yan Y, Ma L, Hou B, He Y, Zhang L, Niu Z, Song J, Pang $X$ and Yang X: Effects of the Nrf2 modulator salvianolic acid A alone or combined with metformin on diabetes-associated macrovascular and renal injury. J Biol Chem 291: 22288-22301, 2016.

This work is licensed under a Creative Commons Attribution-NonCommercial-NoDerivatives 4.0 International (CC BY-NC-ND 4.0) License. 